\title{
Review of Recent Progress in Robotic Knee Prosthesis Related Techniques: Structure, Actuation and Control
}

\author{
Yuanxi Sun ${ }^{1 *}$, Hao Tang², Yuntao Tang ${ }^{3}$, Jia Zheng ${ }^{4}$, Dianbiao Dong, ${ }^{5,6}$ Xiaohong Chen ${ }^{3}$, Fuqiang Liu ${ }^{1}$, \\ Long Bai ${ }^{1}$, Wenjie Ge ${ }^{5}$, Liming Xin ${ }^{7,8}$, Huayan Pu$^{8}$, Yan Peng ${ }^{8}$, Jun Luo ${ }^{1}$ \\ 1. State Key Laboratory of Mechanical Transmission, Chongqing University, Chongqing 400044, China \\ 2. School of Mechanical Engineering, Tianjin University, Tianjin 300072, China \\ 3. College of Mechanical Engineering, Chongqing University, Chongqing 400044, China \\ 4. School of Advanced Manufacturing Engineering, Chongqing University of Posts and Telecommunications, Chongqing 400065, China \\ 5. School of Mechanical Engineering, Northwestern Polytechnical University, Xi' an 710072, China \\ 6. Department of Mechanical Engineering, Vrije Universiteit Brussel, 1050 Brussels, Belgium \\ 7. Department of Mechanical \& Industrial Engineering, University of Toronto, Toronto M5S 2E8, Canada \\ 8. Research Institute of Unmanned Surface Vessel (USV) Engineering, Shanghai University, Shanghai 200444, China
}

\begin{abstract}
As the essential technology of human-robotics interactive wearable devices, the robotic knee prosthesis can provide above-knee amputations with functional knee compensations to realize their physical and psychological social regression. With the development of mechanical and mechatronic science and technology, the fully active knee prosthesis that can provide subjects with actuating torques has demonstrated a better wearing performance in slope walking and stair ascent when compared with the passive and the semi-active ones. Additionally, with intelligent human-robotics control strategies and algorithms, the wearing effect of the knee prosthesis has been greatly enhanced in terms of stance stability and swing mobility. Therefore, to help readers to obtain an overview of recent progress in robotic knee prosthesis, this paper systematically categorized knee prostheses according to their integrated functions and introduced related research in the past ten years (2010-2020) regarding (1) mechanical design, including uniaxial, four-bar, and multi-bar knee structures, (2) actuating technology, including rigid and elastic actuation, and (3) control method, including mode identification, motion prediction, and automatic control. Quantitative and qualitative analysis and comparison of robotic knee prosthesis-related techniques are conducted. The development trends are concluded as follows: (1) bionic and lightweight structures with better mechanical performance, (2) bionic elastic actuation with energy-saving effect, (3) artificial intelligence-based bionic prosthetic control. Besides, challenges and innovative insights of customized lightweight bionic knee joint structure, highly efficient compact bionic actuation, and personalized daily multi-mode gait adaptation are also discussed in-depth to facilitate the future development of the robotic knee prosthesis.
\end{abstract}

Keywords: bionic, robotic knee prosthesis, prosthetic knee, mechanism, actuation, control

Copyright $\odot$ The author(s) 2021.

\section{Introduction}

With the rapid development of human society, traffic accidents, industrial injuries, human-made disasters, war, and diseases have led to an increasing number of patients with limb function losses. These patients are unable to achieve daily life due to physical disability, and huge psychological burdens caused more significant harm to themselves and their families. According to the World Disability Report of the World Health Organization (WHO), approximately $15 \%$ of people (worldwide) currently have some form of disability, $2 \%$ to $4 \%$ of whom face severe functional disorders.

For patients with lower limb disabilities, the primary goal of self-care rehabilitation is to restore their limb functions, where the robotic knee prosthesis acts as the primary functional component. The robotic knee prosthesis enables them to walk by controlling the shank posture, providing necessary knee joint torque and swing damping, and stabilizing the lower limb, etc., realizing both the physical and psychological social return of these patients. Fig. 1 shows some typical commercial knee prostheses that have been widely applied for above-knee amputees.

\footnotetext{
*Corresponding author: Yuanxi Sun

E-mail: sunyuanxi@cqu.edu.cn
} 


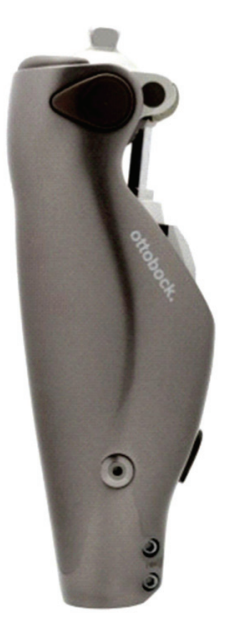

(a)

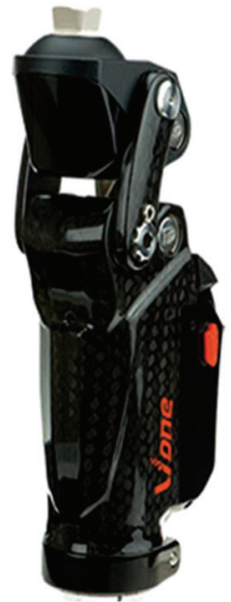

(b)

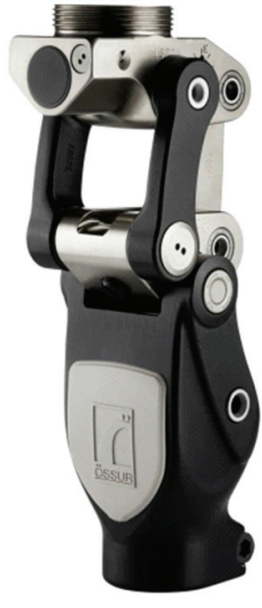

(c)
Fig. 1 Typical commercial knee prostheses. (a) Uniaxial knee prosthesis: C-Leg (Ottobock); (b) four-bar knee prosthesis: V One (TEH LIN); (c) six-bar knee prosthesis: Total Knee (Ossur).

From the most primary to the most advanced requirements, the robotic knee prosthesis should provide the following functions:

(1) Support function. The support function is the most basic function of the robotic knee prosthesis, which enable a specific damping or self-locking function when the patient stands, thereby supporting the patient to walk stably. Realizing this function can make the patient get out of the difficult situation of being unable to walk.

(2) Swing function. The swing function can provide the patients with the swing actuation or damping, thereby enabling the partial or complete swing motion of the prosthetic shank. Realizing this function can improve/normalize the walking gait of the disabled lower limb.

(3) Active actuation. In addition to necessary support and swing functions, the robotic knee prosthesis should also provide actuating torques for specific lower limb movements such as level-ground walking, stair and ramp ascent/descent, squatting, running, etc. Because the dynamic characteristics and motion laws of the robotic knee prosthesis vary in different locomotion modes, the implementations of active actuation for different locomotion modes of the robotic knee prosthesis require special investigations and designs. Realizing as many active locomotion modes as possible will significantly increase the rehabilitation effect of the robotic knee prosthesis.
(4) Automatic control. An automatic robotic knee prosthesis is capable of perceiving the willingness of the patient and move according to expected/desired rules. The more intelligent the automatic control is, the better the rehabilitation effect the patient will obtain.

According to actuation and automation characteristics, the robotic knee prostheses can be classified into the passive (automatic) robotic knee prosthesis, the semi-active (automatic) robotic knee prosthesis, and the active (automatic) robotic knee prosthesis, as shown in Fig. 2. The passive robotic knee prosthesis is the most widely applied robotic knee prosthesis due to its low prices, which can only provide the patients with function (1). Unlike the purely passive robotic knee prosthesis, the semi-active prosthetic knee is a more high-end robotic knee prosthesis in the market, which can provide the patients with functions (1) and (2). Compared with the passive and the semi-active robotic knee prostheses, the active robotic knee prosthesis can realize all the functions (1), (2) and (3), which is currently the most advanced robotic knee prosthesis for above-knee amputees. If these prosthetic knees are designed with automatic functions, then the function (4) described above can be provided. The mutual relationships between these robotic knee prostheses are listed in Fig. 2.

To realize the functional compensation of the human knee joint, the following design criteria should be met:

(1) Structure. The robotic knee prosthesis must first meet the size and functional requirements of its structure. An excellent prosthetic knee structure can effectively improve its mechanical properties and bionic performance, thus laying the foundation for the movement and gait diversity of the robotic knee prostheses.

(2) Actuation. The robotic knee prosthesis needs active actuation/damping to normalize the gait of the affected side. Selecting a suitable actuating technique can effectively improve the walking gait of the robotic knee prosthesis and is beneficial to enhancing the actuating characteristics of the robotic knee prosthesis.

(3) Control. The control technology of the robotic knee prosthesis directly determines its adaptability and practicability. Improving the automatic control level of the robotic knee prosthesis helps to achieve a more bionic and advanced performance of the robotic knee prosthesis. 


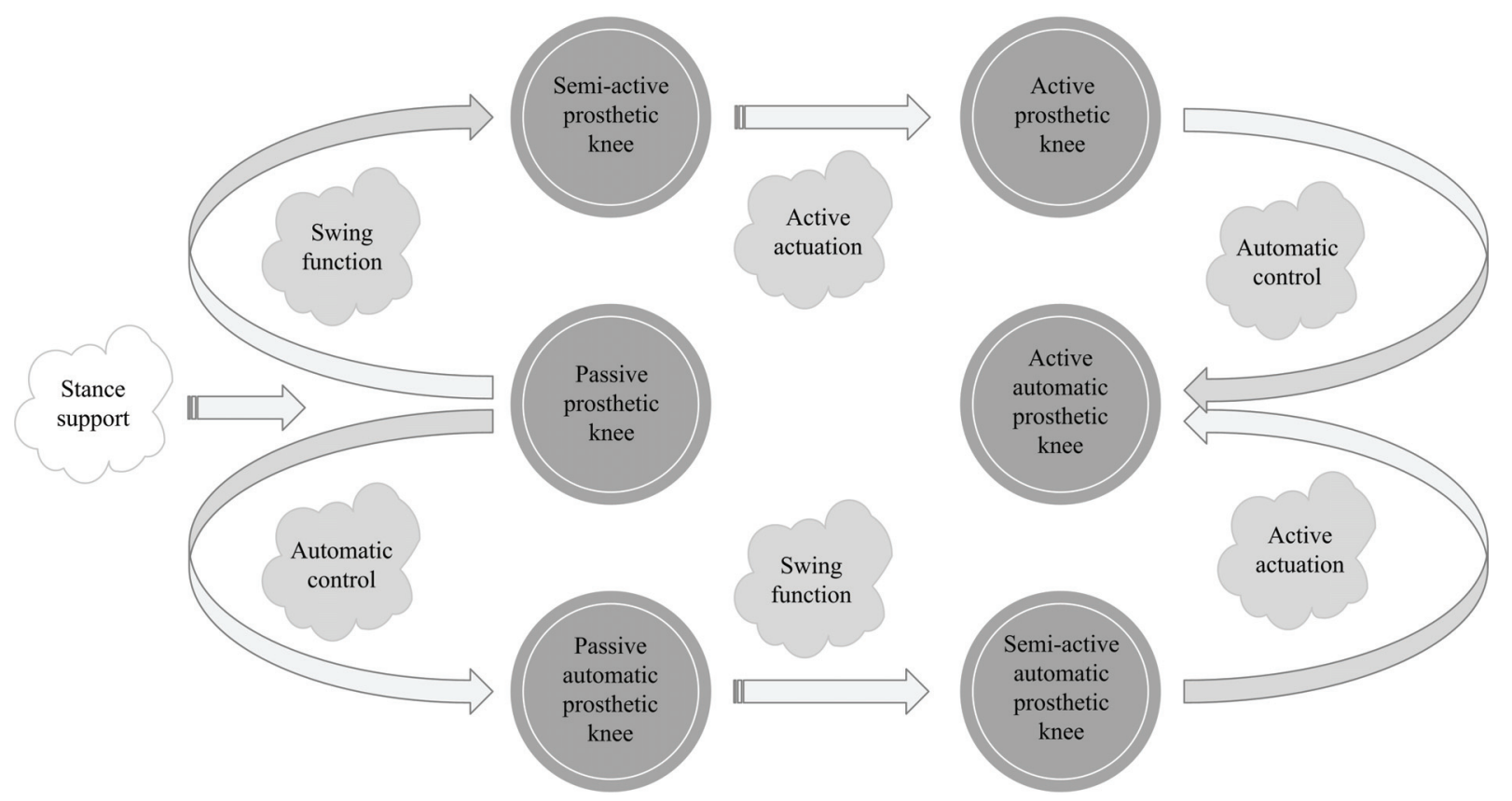

Fig. 2 Functions and mutual relationships between different types of robotic knee prostheses.

Therefore, to help relevant readers better understand the current research status and progress of the robotic knee prosthesis, this review compared and summarized related contributions in terms of structural design, actuating technology, and control methods in the past ten years (2010-2020). The literature survey and acquisition method are as follows: the authors searched Google Scholar for "robotic knee prosthesis", "prosthetic knee joint", "bionic prosthetic knee joint", "prosthetic exoskeleton robot", and "prosthetic knee exoskeleton", and obtained 16700, 17700, 5170, 14400, 8550 results. Then, the authors selected 458 articles of general significance through the following process: (a) The results are ranked by relevance using the algorithm provided by Google; (b) divide the past ten years into ten periods and select the top $1 \%$ articles of each keyword in each period; (c) ignore those articles that do not include "rehabilitation equipment" or belong to the category of biological research. After checking abstracts of the selected articles, 66 highly relevant documents were selected for in-depth investigation. The main contributions of this paper are as follows:

(1) Systematic classifications of robotic knee prosthesis functions are presented, and related research in terms of structures, actuation, and control in the past ten years are introduced.

(2) Quantitative and qualitative analysis and comparison of robotic knee prosthesis-related techniques are conducted, and their challenges and innovative insights are discussed in detail.

The rest of this review is organized as follows: In section 2, the robotic knee prostheses of different structures are studied and compared; in section $\mathbf{3}$, different actuating strategies of the robotic knee prosthesis are compared and summarized; in section $\mathbf{4}$, available control schemes of the robotic knee prosthesis are introduced and summarized; section $\mathbf{5}$ discussed the research status, and drew some technical issues and development trends of the robotic knee prosthesis; in section 6 , the review is technically concluded.

\section{Structural design of the robotic knee pros- thesis}

Proper structural design of the robotic knee prosthesis can provide the patients with better bionic performance, dynamic characteristics, and motion stability, and can facilitate the prosthetic actuation. At present, the study of the prosthetic structure mainly includes two types, namely the uniaxial one and the multi-axial one. 


\subsection{Uniaxial robotic knee prosthesis}

The uniaxial prosthetic knee uses a single hinge to achieve knee motion. Because the working principle of the uniaxial robotic knee prosthesis is simple, its structural research mainly focuses on the realization of special knee functions, such as stance self-locking, redundant actuation, and stair ascent/descent, etc.

Andrysek et al. proposed a uniaxial robotic knee prosthesis (Fig. 3a) with a self-locking function in the stance phase ${ }^{[1]}$. The pylon bone can be pushed by the foot support force to push the knee lock clockwise around the control axis in the stance phase, thereby locking the thigh component and the robotic knee prosthesis to form a stance self-locking. In the swing phase, the lower limb movement drives the knee lock to rotate counterclockwise around the control axis, thereby disengaging the prosthetic knee from the self-locking state and providing required damping by the friction washer. The robotic knee prosthesis achieves stance self-locking and swinging damping control in the experimental stage through a purely mechanical structure, which is of high walking reliability. Arelekatti et al. also designed a self-locking/clutching single-axis knee joint ${ }^{[2,3]}$ (Fig. 3b) by using the latch mechanism in the stance phase, and Ramakrishnan et al. proposed a stance self-locking/ clutching method based on the gear-rack mechanism ${ }^{[4]}$.
Moreover, Liu et al. theoretically proposed a redundantly actuated uniaxial robotic knee prosthesis by designing the locking mechanism with a torsion spring ${ }^{[5]}$. The robotic knee prosthesis can lock the torsion spring in the stance phase via a cam mechanism to provide redundant control torque in the stance phase. When in the swing phase, the cam mechanism leaves the locked state and releases the torsion spring, thereby disengaging the robotic knee prosthesis from the redundant actuation state. In addition, Inoue (Fig. 3c) et al. proposed a uniaxial robotic knee prosthesis for stair ascent ${ }^{[6]}$, which can realize the stance position limit in stair ascent via the crank slider mechanism, limiter, and spring, and can assist the knee joint extension when the sole was exerted.

To improve the overall performance of the uniaxial robotic knee prosthesis, Lenzi et al. implemented a lightweight robotic knee prosthesis with a new hybrid actuating system that can realize passive and active modes of operation ${ }^{[7]}$. The hybrid knee joint uses a spring-damper system in combination with an electric motor and transmission system to provide stairs mobility, which weighs only $1.7 \mathrm{~kg}$ (including batteries) and can provide up to $125 \mathrm{~N} \cdot \mathrm{m}$ of repetitive torque. Similarly, Lovasz et al. designed a hydraulically driven uniaxial robotic knee prosthesis ${ }^{[8]}$ based on a geared inverted

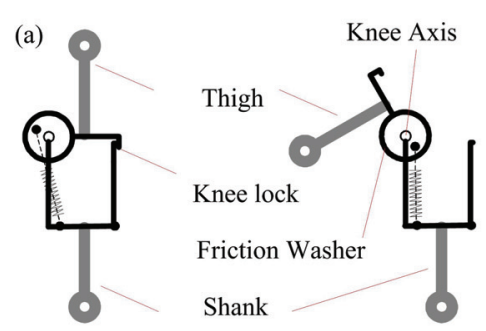

(d)

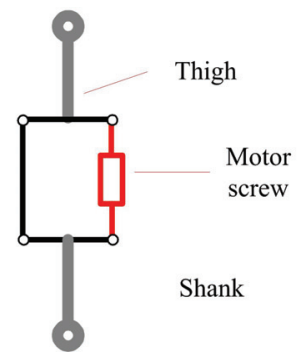

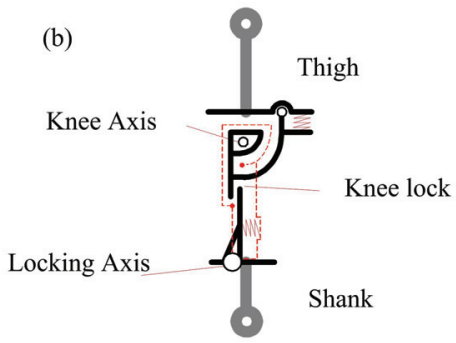

(e)

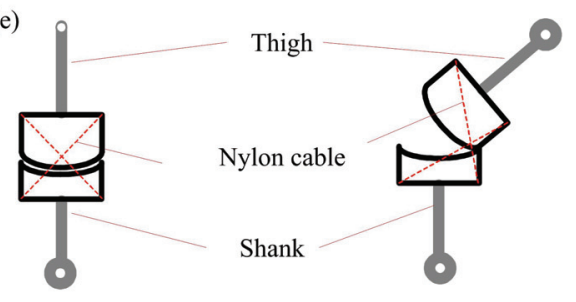

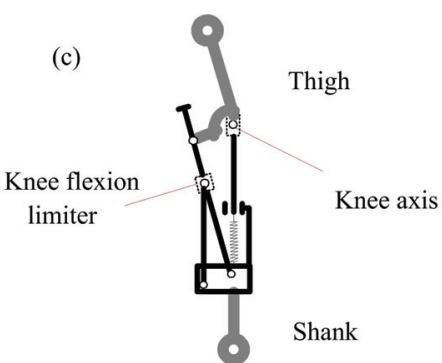

(f)

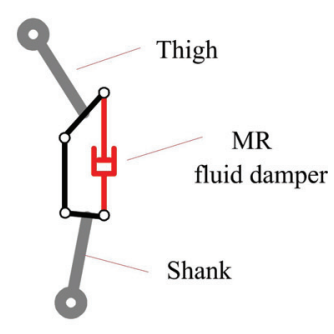

Fig. 3 Schematic diagrams of uniaxial and multi-axial robotic knee prostheses. (a) Uniaxial knee prosthesis with friction cone for stance self-locking; (b) uniaxial knee prosthesis with latch mechanism for stance self-locking; (c) uniaxial knee prosthesis with limiter and spring for stair ascent; (d) four-bar knee prosthesis with a variable linkage for gait adjustment; (e) nylon anti-parallel four-bar knee prosthesis with adjustable knee elasticity; (f) four-bar knee prosthesis with magnetorheological fluid damper for swing damping. 
crank slider mechanism. A hydraulic cylinder hinged on its shank linkage acts as the slider mechanism to drive the geared linkage mechanism, thereby providing actuating torques for the robotic knee prosthesis. Dabiri et al. designed a uniaxial robotic knee prosthesis ${ }^{[9]}$ that can mimic human muscle characteristics. The prosthesis can simulate the movement characteristics of the knee joint via two pneumatic muscles, thereby providing a better walking gait for the above-knee amputees. In addition, Hoover et al. theoretically proposed a motor-screw-driven uniaxial robotic knee prosthesis ${ }^{[10,11]}$. The motor is hinged to the shank link to actuate the knee joint, thereby achieving a driving effect of $150 \mathrm{~W}$ continuous output power and $500 \mathrm{~W}$ peak output power.

\subsection{Multi-axial robotic knee prosthesis}

The multi-axial robotic knee prosthesis refers to one with a plurality of hinges or a non-fixed shaft, which can be realized by the multi-bar mechanism or the gear mechanism. Compared to uniaxial robotic knee prostheses, the multi-axial robotic knee prostheses have advantages in bionic performance, prosthetic stability, and net energy expenditure.

\subsubsection{Four-bar mechanism}

Due to its simple structure and fine bionic and mechanical properties, the four-bar mechanism has been widely used in the design and application of robotic knee prostheses since the 1980s. In recent years, the research on the four-bar mechanism robotic knee prostheses has been mainly focused on the direction of particular locomotion function, integrated actuation, and elastic deformation.

Demsar et al. developed a commercial four-bar robotic knee prosthesis for alpine skiing ${ }^{[12]}$. It can maintain the stance stability of the amputee while the center of gravity of the patient is maintained in front of the body in a semi-squat state so that the amputee can perform certain sports such as skiing and ice skating. Different from this, Inoue et al. designed a passive four-bar prosthetic knee prototype ${ }^{[13]}$ that can be used in stair ascent. When the prosthetic leg is in contact with the stair ground in a curved state, the hinge of the lower leg linkage is moved into the slot of the side linkage, thereby completing the self-locking of the knee joint under bending in stair ascent. To improve the gait performance of the four-bar knee joint, Awad et al. proposed an experimental prototype of a variable-length four-bar robotic knee prosthesis ${ }^{[14]}$ (Fig. 3d). One of the four-bar linkages is replaced by a motor-screw system. By actuating the screw by the motor, the size of the four-bar mechanism can be adjusted to enable the robotic knee prosthesis to achieve the desired gait. Similarly, Etoundi et al. proposed an experimental model of a deformable four-bar robotic knee prosthesis ${ }^{[15]}$ that can mimic the structure of the human knee joint (Fig. 3e). The robotic knee prosthesis incorporates the shape of the tibia and femur bones and uses an anti-parallel four-bar mechanism made of a stretchable nylon cord to realize the knee function. The force stability of this robotic knee prosthesis is improved, and its flexibility can be adjusted according to the needs of the amputee. In addition, Lu et al. theoretically designed a robotic knee prosthesis based on a flexible four-bar mechanism ${ }^{[16]}$. The shank linkage is made of a flexible material that can change its shape during prosthetic movement, thus providing stable damping and shock absorption in the stance phase.

To improve the walking performance of the four-bar knee joint, Bulea et al. (Fig. 3f) proposed a four-bar mechanism robotic knee prosthesis controlled by a linear magnetorheological fluid damper ${ }^{[17]}$. Two ends of the linear magnetorheological fluid damper are installed on the thigh and the shank linkages of the four-bar mechanism, which can provide the patient with a maximum swing damping of $64.5 \mathrm{~N} \cdot \mathrm{m}$ theoretically. Li et al. designed a four-bar mechanism robotic knee prosthesis integrated with a meniscus ${ }^{[18]}$, so that the robotic knee prosthesis can bear a larger load while exercising, and has the function of buffering shock absorption. Besides, $\mathrm{Fu}$ and Zhang et al. also designed a four-bar robotic knee prosthesis based on parallel springs and dampers ${ }^{[19,20]}$ to stably adjust the swing speed of the prosthetic knee in the swing phase and absorb vibration and maintain stability in the stance phase. To improve the cost-effectiveness of robotic knee prostheses, Arelekatti et al. designed a low-cost passive four-bar prosthetic knee for daily use of amputees in developing countries ${ }^{[21]}$. The mechanism is implemented based on two functional modules: an automatic early attitude lock for stability, and a differential friction 
damping system for later attitude and swing control. The results of field tests showed that the early posture locking performance is satisfactory, and the prototype achieves a stable posture transition by promptly launching post-posture flexion.

\subsubsection{Multi-axial mechanism}

In addition to the four-bar mechanism, other multi-bar mechanisms and non-circular gear mechanisms are gradually applied to the robotic knee prosthesis. These mechanisms contain more design parameters than the four-bar mechanism, providing better bionic knee performance after proper mechanism design. For example, Sun et al. designed a geared five-bar mechanism robotic knee prosthesis, which has superior bionic performance compared with the four-bar one ${ }^{[22]}$. The Instantaneous Center of Rotation (ICR) can be fine-tuned via adjusting the gear ratio of the prosthetic mechanism, which improves the customizable level of the robotic knee prosthesis. Dalessio et al. theoretically designed a robotic knee prosthesis based on the non-circular gear ${ }^{[23]}$. It uses the axial plane optimization in the Revolute-Revolute-Spherical-Spherical (RRSS) space to obtain the specific parameters of the non-circular gear, which can ideally simulate the rotation characteristics of the human knee joint. In addition, Wu et al. proposed a robotic knee prosthesis based on the incomplete gear-linkage structure ${ }^{[24]}$. The robotic knee prosthesis is formed by two rod-connected incomplete gears fixed to the thigh and the shank linkage, which can provide the right ankle trajectory and is of easy control like the uniaxial knee joint.

\subsubsection{Design methodology}

Wu et al. proposed an optimization method of the four-bar robotic knee prosthesis ${ }^{[25]}$, which uses the ICR of the human knee joint as the optimization target for the four-bar mechanism parameters to provide better bionic performance for patients than conventional ones. Zhang et al. proposed a four-bar robotic knee prosthesis optimization method based on the ideal human ankle trajectory ${ }^{[26]}$. The optimized four-bar robotic knee prosthesis can provide a better ankle trajectory to the patient. Furthermore, Ghaemi et al. proposed a force analyzing and optimizing method for the knee joint in flexible multi-bar prosthetic joints ${ }^{[27]}$. By replacing a rigid hinge in the conventional multi-bar mechanism (such as the four-bar mechanism, the six-bar mechanism, etc.) with a flexible hinge, the optimization objective of the flexible joint can be established, thereby reducing the knee joint control torque. In addition, Pfeifer et al. proposed a four-bar mechanism optimization model based on the motor-screw system ${ }^{[28,29]}$. The installation position of the motor-screw is optimized to provide desired actuating torques for the robotic knee prosthesis.

\subsection{Summary of the structural design of the robotic knee prosthesis}

The qualitative summary of this section is listed in Table 1. To facilitate readers to obtain a clear and in-depth overview of the introduced prosthetic knee structures, the authors also made a quantitative evaluation of the function and performance differences between the uniaxial, the four-bar, and the multi-axial prosthetic knee structures, namely, functionality (refers to the prosthetic function that can be achieved as a substitute for the knee joint), performance (refers to the motion effect that can be achieved as a knee joint), efficiency (refers to the energy efficiency or consumption of its actuation or movement), and mobility (refers to the motion performance limited by its kinematics and dynamics performance, which is also listed in the last column of Table 1). Each aspect of the introduced prosthetic knee structure is scored from low to high via the five-pointed stars.

\section{Actuating techniques of the robotic knee prosthesis}

The actuating technique directly affects the mobility functions of the robotic knee prosthesis, which can be divided into the following three categories according to their characteristics:

(1) Non-actuated/passive: This category of robotic knee prostheses is driven by the above-knee amputee via the residual of the thigh, which can only provide auxiliary functions such as stance self-locking and free/damped swinging in the swing phase. Advanced functions such as shock absorbing, stance flexion, stair ascent, etc., can be specially designed via modifying the prosthetic mechanism with limiters or elastic components. 
Table 1 Research summary and comparison of different robotic knee prosthesis structures

\begin{tabular}{|c|c|c|c|c|c|c|c|c|c|}
\hline \multicolumn{10}{|c|}{ Uniaxial } \\
\hline Refs. & Features & Realization & Actuation & Progress & Functionality & Performance & Efficiency & Mobility & $\begin{array}{l}\text { Kinematics and } \\
\text { dynamics }\end{array}$ \\
\hline$[1]$ & $\begin{array}{c}\text { Stance } \\
\text { self-locking/ } \\
\text { swing damping }\end{array}$ & $\begin{array}{l}\text { Elastic locking } \\
\text { /friction cone }\end{array}$ & Passive & Prototype & $\star$ & $\star \star \star$ & $\star \star$ & $\star \star$ & $\begin{array}{l}\text { Controllable } \\
\text { stance phase }\end{array}$ \\
\hline$[2,3]$ & $\begin{array}{c}\text { Stance } \\
\text { self-locking }\end{array}$ & Latch mechanism & Passive & Prototype & $\star \star \star$ & $\star \star \star \star$ & $\star \star \star$ & $\star \star$ & $\begin{array}{l}\text { Smooth transi- } \\
\text { tion between } \\
\text { stance and swing }\end{array}$ \\
\hline [4] & $\begin{array}{c}\text { Stance } \\
\text { self-locking }\end{array}$ & Rack-pinion & Passive & Theory & $\star \star \star$ & $\star \star$ & $\star \star \star$ & $\star \star \star$ & $\begin{array}{l}12 \text { walking } \\
\text { modes }\end{array}$ \\
\hline$[5]$ & $\begin{array}{l}\text { Redundant actua- } \\
\text { tion }\end{array}$ & Cam/spring & Passive & Theory & $\star \star$ & $\star \star$ & $\star \star$ & $\star \star \star$ & $\begin{array}{l}\text { Redundant } \\
\text { torque }\end{array}$ \\
\hline$[6]$ & Stair ascent & Limiter/spring & Passive & Theory & $\star$ & $\star \star \star \star$ & $\star \star$ & $\star \star \star$ & $0^{\circ}-88^{\circ}$ flexion \\
\hline$[7]$ & $\begin{array}{l}\text { Active level } \\
\text { walking/stair } \\
\text { ascent }\end{array}$ & $\begin{array}{l}\text { spring-damper/ } \\
\text { motor }\end{array}$ & Hybrid & $\begin{array}{l}\text { Commer- } \\
\text { cialization }\end{array}$ & $\star \star \star \star$ & $\star \star \star \star \star$ & $\star \star \star \star$ & $\star \star \star \star$ & $1.7 \mathrm{~kg}, 125 \mathrm{~N} \cdot \mathrm{m}$ \\
\hline$[8]$ & Active actuation & $\begin{array}{l}\text { Geared inverse } \\
\text { crank slider } \\
\text { mechanism }\end{array}$ & Active & Prototype & $\star \star \star$ & $\star \star$ & $\star \star \star$ & $\star \star$ & $\begin{array}{l}\text { Aerodynamic } \\
\text { damping }\end{array}$ \\
\hline [9] & $\begin{array}{l}\text { Knee muscle } \\
\text { Imitation }\end{array}$ & $\begin{array}{l}\text { Pneumatic } \\
\text { muscle }\end{array}$ & Active & Prototype & $\star \star$ & $\star \star$ & $\star \star$ & $\star \star \star \star$ & 7 gait modes \\
\hline$[10,11]$ & Active actuation & Motor-screw & Active & Prototype & $\star \star$ & $\star \star$ & $\star$ & $\star \star \star \star$ & $\begin{array}{c}150 \mathrm{~W} \text { output, } \\
0^{\circ}-90^{\circ} \\
\text { flexion }\end{array}$ \\
\hline \multicolumn{10}{|c|}{ Four-bar } \\
\hline$[12]$ & Alpine skiing & $\begin{array}{l}\text { Flexible limit- } \\
\text { er/squat design }\end{array}$ & Passive & $\begin{array}{l}\text { Commer- } \\
\text { cialization }\end{array}$ & $\star$ & $\star \star \star$ & $\star \star$ & $\star \star$ & $\begin{array}{l}\text { Large load and } \\
\text { skiing }\end{array}$ \\
\hline$[13]$ & Stair ascent & $\begin{array}{l}\text { Variable hinge } \\
\text { four-bar mecha- } \\
\text { nism/limiter }\end{array}$ & Passive & Prototype & $\star \star \star \star$ & $\star \star$ & $\star \star \star$ & $\star \star \star \star \star$ & Preventing \\
\hline [14] & fine gait & $\begin{array}{l}\text { Four-bar mech- } \\
\text { anism with a } \\
\text { variable linkage }\end{array}$ & Active & Prototype & $\star \star \star$ & $\star \star \star$ & $\star \star \star$ & $\star \star$ & $\begin{array}{l}\text { accidental buck- } \\
\text { ling }\end{array}$ \\
\hline$[15]$ & $\begin{array}{l}\text { Bionic struc- } \\
\text { ture/adjustable } \\
\text { elasticity }\end{array}$ & $\begin{array}{l}\text { Anti-parallel } \\
\text { four-bar mecha- } \\
\text { nism/nylon }\end{array}$ & Passive & Prototype & $\star \star \star$ & $\star \star \star$ & $\star \star$ & $\star \star \star$ & $\begin{array}{l}\text { High torque and } \\
\text { low speed }\end{array}$ \\
\hline$[16]$ & $\begin{array}{l}\text { Elastic damp- } \\
\text { ing/shock } \\
\text { absorption }\end{array}$ & $\begin{array}{l}\text { Linkage topo- } \\
\text { logical flexible } \\
\text { deformation }\end{array}$ & Passive & Prototype & $\star \star \star$ & $\star \star \star \star$ & $\star \star$ & $\star \star$ & $\begin{array}{l}\text { High stiffness } \\
\text { and strength }\end{array}$ \\
\hline$[17]$ & $\begin{array}{l}\text { Intelligent } \\
\text { swing damp- } \\
\text { ing }\end{array}$ & $\begin{array}{l}\text { Magnetorheo- } \\
\text { logical fluid } \\
\text { damper }\end{array}$ & Semi-active & Prototype & $\star \star$ & $\star \star \star$ & $\star \star \star$ & $\star \star \star$ & Shock absorption \\
\hline$[21]$ & $\begin{array}{l}\text { Normative } \\
\text { gait }\end{array}$ & $\begin{array}{c}\text { Attitude } \\
\text { lock/differential } \\
\text { friction damping }\end{array}$ & Passive & Prototype & $\star \star \star \star$ & $\star \star$ & $\star \star \star$ & $\star \star \star \star$ & $\begin{array}{c}64.5 \mathrm{~N} \cdot \mathrm{m} \text { damp- } \\
\text { ing }\end{array}$ \\
\hline \multicolumn{10}{|c|}{ Multi-axial } \\
\hline$[22]$ & $\begin{array}{l}\text { Bionic struc- } \\
\text { ture/adjustable } \\
\text { ICR }\end{array}$ & $\begin{array}{l}\text { Geared five-bar } \\
\text { mechanism }\end{array}$ & Active & Prototype & $\star \star \star \star$ & $\star \star \star$ & $\star \star$ & $\star \star \star \star$ & Customized ICR \\
\hline$[23]$ & $\begin{array}{l}\text { Bionic struc- } \\
\text { ture }\end{array}$ & $\begin{array}{c}\text { non-circular } \\
\text { gear }\end{array}$ & Passive & Theory & $\star \star \star \star$ & $\star \star \star \star$ & $\star \star \star$ & $\star \star \star \star$ & $\begin{array}{l}\text { RRSS single } \\
\text { DOF coupling }\end{array}$ \\
\hline$[24]$ & $\begin{array}{l}\text { Simple struc- } \\
\text { ture }\end{array}$ & $\begin{array}{l}\text { Gear-linkage } \\
\text { mechanism }\end{array}$ & Passive & Theory & $\star \star \star$ & $\star$ & $\star \star$ & $\star \star$ & $\begin{array}{l}\text { Fine ankle tra- } \\
\text { jectory }\end{array}$ \\
\hline
\end{tabular}


When an amputee wears a robotic knee prosthesis of this category, the rehabilitation effect of the robotic knee prosthesis is limited by the prosthetic control ability of himself. In addition, since the human knee joint continuously consumes energy when walking, the non-actuated/passive robotic knee prosthesis will not achieve as desired walking gait as expected.

(2) Rigid actuation: This category of robotic knee prostheses is actuated directly by the actuating components such as motors, pneumatic/hydraulic cylinders, and magnetorheological fluid actuators, etc., which can provide required actuation torque with easy control for amputees under various walking conditions. However, because the motion characteristics of the robotic knee prosthesis are highly nonlinear and unpredictable, rigid actuation may be susceptible to some defects such as slow response, high actuating linearity and low driving precision, etc., which might result in unexpected and unsatisfactory robotic actuation. In addition, rigid actuation may not cope with sudden changes in knee joint movement, such as impact, emergency stop, etc., resulting in reduced walking practicality in daily life.

(3) Elastic actuation: the robotic knee prosthesis is actuated by combining the actuating component and the elastic element. The elastic actuation can realize energy absorption and reuse and is of high control precision, which can enable the robotic knee prosthesis to adapt to various motion situations. The core idea behind the elastic actuation is to use appropriately designed elastic elements to assist the robotic actuation, thus achieving power reduction as well as improving its actuating accuracy and anti-impact performance. Therefore, the elastic actuation has become a hotspot research direction in terms of the robotic knee prosthesis.

\subsection{Rigid actuation}

In recent years, the research of rigid actuation has been mainly focused on the direction of high-performance magnetorheological fluid actuators and special motors to achieve miniaturization, weight reduction, and energy saving.

Guo et al. designed a multi-functional rotary actuator $^{[30]}$ that combines a motor and a magnetorheological fluid damper (Fig. 4a). The rotary actuator is divided into two parts: a motor and a magnetorheologi- cal fluid clutch/brake. The motor part is composed of the coil fixed to the housing and the permanent magnet fixed to the rotor formed by the magnetorheological fluid clutch/braking part. When the rotor is energized, the clutching state between the rotor and the output shaft can be manipulated. The rotary actuator can provide active torque in the swing phase through its motor part on the robotic knee prosthesis, as well as stance self-locking and damping functions in the stance phase using the magnetorheological fluid damper. In the meantime, Guðmundsson optimized a magnetorheological fluid damper with high working output torque and low closed output damping ${ }^{[31]}$. The authors used the bi-objective optimization method to optimize the specific configuration of the magnetorheological fluid damper and tested appropriate magnetorheological fluid parameters from 22 kinds of magnetorheological fluid materials and their mixtures, resulting in better damping performance than standard commercial magnetorheological fluid dampers. What is more, Solomon et al. designed a magnetorheological damping valve that can control the swing damping of the robotic knee prosthesis, where the damping valve is limited to the required cylindrical volume defined by its radius and height ${ }^{[32]}$. The results of the Response Surface method Mapping(RSM) Finite Element Analysis (FEA) show that the weight of the damper is reduced by $71 \%$ compared with existing magnetorheological dampers while a nearly normal swing phase trajectory can also be guaranteed.

For the motor-based actuators, Furuya et al. designed a high-thrust spiral motor ${ }^{[33]}$ for joint actuation, the motor stator and rotor of which are in the spiral shape (Fig. 4b). When the stator is energized, the rotor is driven to rotate and advances axially along the spiral gap of the stator, thereby generating a theoretical thrust of $101 \mathrm{~N}$. Additionally, Bogert et al. theoretically proposed a rotary hydraulic actuator that utilizes high/low-pressure accumulators for energy storage and release ${ }^{[34,35]}$. The high/low-pressure accumulator control valves are opened and closed in a particular order of operation to provide active power and damping control for the prosthetic knee. The authors also theoretically designed a prosthetic knee actuator that can realize electrical energy storage $^{[36]}$ via the supercapacitor. The released mechanical energy of the robotic knee prosthesis can be gathered 
(a)
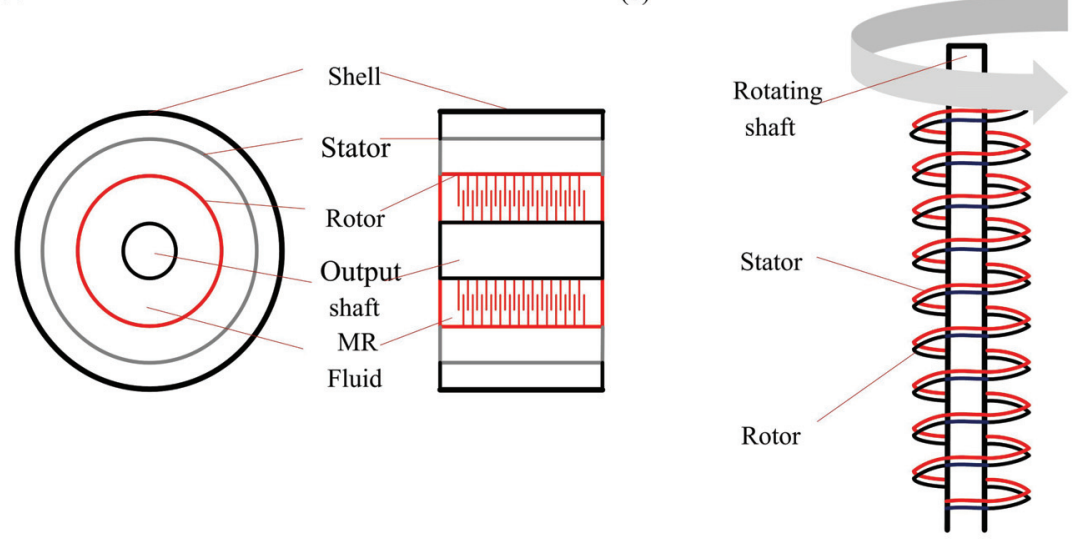

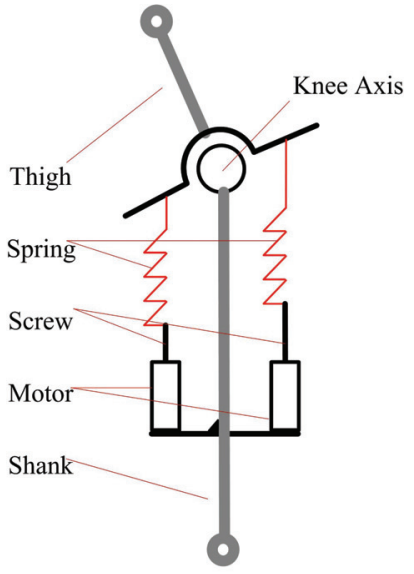

(d)

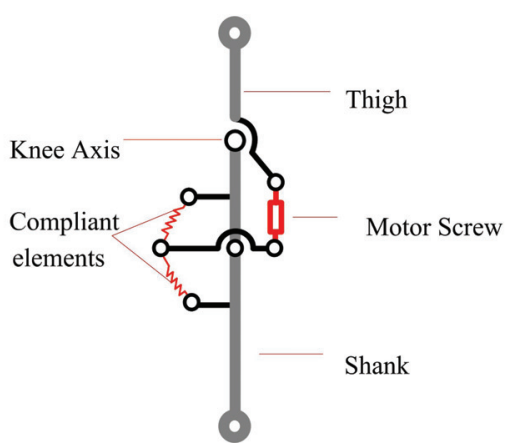

(e)

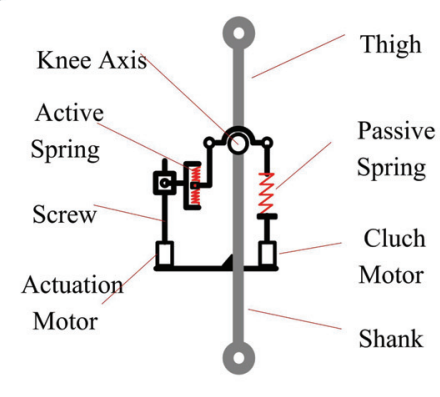

(f)

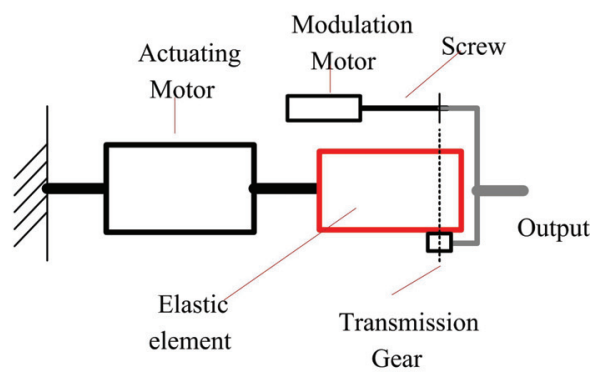

Fig. 4 Schematic diagrams of actuators for the robotic knee prostheses. (a) Multi-functional rotary actuator with active torque or damping/locking function; (b) axial motor with high axial thrust; (c) agonist-antagonist actuation with dual series elastic actuators; (d) series/parallel elastic actuator and variable stiffness actuation with both series and parallel elastomers; (e) hybrid series elastic actuator with passive clutchable parallel elastomer; (f) variable stiffness actuator with cylindrical elastomer.

by the super capacity and reused for prosthetic actuation when needed.

\subsection{Elastic actuation}

Due to its high control/actuation accuracy and energy absorption/reuse features, the elastic actuation has become a research hotspot of the prosthetic actuation. At present, the elastic actuation mainly develops toward the bionic series/parallel elastic actuation, series-parallel/parallel-series hybrid elastic actuation, and the variable stiffness actuation.

Martinez-Villalpando et al. designed an antagonistic active robotic knee prosthesis (Fig. 4c) based on the motor-screw series elastic actuator ${ }^{[37]}$. Two sets of series elastic actuators are utilized to provide the muscle-like agonist-antagonist actuation, thereby achieving a better lower limb gait than conventional actuation. The authors also designed a clutchable series elastic actuated robotic knee prosthesis, which can effectively enhance the en- ergy utilization rate ${ }^{[38,39]}$. In addition, Hoover et al. theoretically proposed a series elastic actuator based on the variable impedance agonist-antagonist muscle model ${ }^{[40]}$, which can provide actuation and damping characteristics of human muscles to realize knee self-locking and stability maintenance. Moreover, Grimmer and Seyfarth theoretically proposed a series elastic actuated uniaxial knee that can mimic the muscle function of the lower extremities of the human body ${ }^{[41]}$, thereby achieving the reduction in the peak power and energy consumption of the motor.

Pfeifer et al. proposed a series-parallel hybrid elastic actuation technique (Fig. 4d) for the robotic knee prosthesis ${ }^{[29]}$, the lever in which is adjusted via the motor-screw to regulate the working condition of the actuator, thus providing expected knee actuating torque. The parallel spring in the robotic knee prosthesis acts as an auxiliary actuation to reduce the power of the motor. This proposed elastic actuator can realize the function of 
variable knee stiffness like the human knee, which is biomimetically closer to the human knee joint in terms of knee dynamics. Similarly, Flynn et al. have developed a new type of semi-active actuator with lockable parallel springs (Fig. 4e) for the knee joint of the bionic robot ${ }^{[42]}$, which is able to provide approximate behavior of a healthy knee during most gait cycles in level-ground walking. The actuator can also be used for functional tasks such as climbing stairs. Compared with passive or variable damping robotic knee prosthesis, the proposed actuator can effectively reduce energy consumption and improve the level-ground walking behavior.

Schuy et al. designed a series elastic actuator (Fig. 4 f) with variable torsional stiffness ${ }^{[3,44]}$, two motors in which are responsible for respective actuation and variable stiffness adjustment. When the meshing position of the counter bearing and the cylindrical elastic component changes, the output torque changes accordingly. The elastic actuator has been experimentally proven to consume less energy in adjusting the elastic output without adjusting the mechanism. Moreover, Wentink et al. also proposed a theoretical model of variable stiffness elastic actuator for the prosthetic joint ${ }^{[45]}$, demonstrating the superiority of the variable stiffness actuator over a conventional series elastic actuator.

\subsection{Summary of the actuation techniques of the ro- botic knee prosthesis}

For the actuation of the prosthetic knee joint, the detailed summary of this section is listed in Table 2. To provide readers with an intuitive overview of the introduced actuation techniques for the robotic knee prostheses, this section made a quantitative evaluation of the function and performance differences between the rigid actuation and the elastic actuation. The evaluation was mainly carried out from four aspects, including the implementation (refers to the level of realizability of the actuator), performance (refers to the continuous and the maximum output torques and speeds of the actuator), functionality (refers to whether the actuator can provide the prosthetic knee joint with bionic actuation in natural gaits), and efficiency (refers to the power efficiency or the power consumption of the actuator when providing various knee motion). Each aspect of the introduced actuation technique is scored from low to high via the five-pointed stars.

\section{Control techniques of the robotic knee prosthesis}

With the development of computer science, mechatronics, and embedded programming, as well as the progress of signal processing and pattern recognition techniques, the control of the robotic knee prostheses has become more and more volitional and intelligent. According to whether the intention of the above-knee amputee is involved in the control process, the control methods of the robotic knee prosthesis can be divided into the volitional ones and the non-volitional ones. The volitional control usually uses the surface electromyography (sEMG) signal to recognize the intention of the amputees, thereby manipulating the robotic knee prosthesis to achieve various functions. On the contrary, the non-volitional control views the prosthetic as an individual control object, which realizes its autonomous motion control by sensor-based gait detection and planning. The intention of the amputee will not participate in the control process.

In the meantime, the control method of the robotic knee prosthesis can also be divided into categories of automatic control and non-automatic control ${ }^{[46,47]}$. The automatic control means that the robotic knee prosthesis can automatically realize functions in terms of gait adjustment, knee torque adaptation, walking phase switching, etc., while the non-automatic control can only realize essential functions of stance self-locking, simple swing damping, etc. Currently, the automatic control of robotic knee prostheses can be divided into two categories. One is the expert control method, such as the finite state machine, the rule-based control, etc. The other one is the neural network/fuzzy control methods that use autonomous learning reasoning for models and environmental changes. At present, the volitional control and the automatic control have gradually merged into the volitional-automatic fusion control, as shown in Fig. 5.

\section{1 sEMG-based control}

The sEMG signal of the lower residual reflects the intention of the amputee of how to move the lower limbs. sEMG-based prosthetic knee control is usually realized by pattern classification or neural network to identify the 
Table 2 Research summary and comparison of different actuation techniques in robotic knee prostheses

\begin{tabular}{|c|c|c|c|c|c|c|c|c|c|}
\hline \multicolumn{10}{|c|}{ Rigid actuation } \\
\hline Refs & Features & Realization & Methods & Progress & Implementation & Performance & Functionality & Efficiency & Specification \\
\hline$[30]$ & $\begin{array}{l}\text { Mo- } \\
\text { tor-magnetor } \\
\text { heological } \\
\text { fluid actuator } \\
\text { integration } \\
\text { swing } \\
\text { damping }\end{array}$ & $\begin{array}{l}\text { Mo- } \\
\text { tor/magnetorh } \\
\text { eological fluid }\end{array}$ & $\begin{array}{l}\text { magnetorheological } \\
\text { fluid-based motor } \\
\text { stator structure }\end{array}$ & Experiment & $\star \star \star$ & $\star \star \star$ & $\star \star \star \star$ & $\star \star \star$ & $\begin{array}{c}\text { Max output } \\
\text { power } 100 \mathrm{~W} \\
\text { and max power } \\
\text { efficiency } 80 \%\end{array}$ \\
\hline$[31]$ & $\begin{array}{l}\text { High work- } \\
\text { ing } \\
\text { torque/low } \\
\text { closing } \\
\text { damping }\end{array}$ & $\begin{array}{l}\text { Magnetorhe- } \\
\text { ological fluid }\end{array}$ & $\begin{array}{l}\text { Structural and } \\
\text { magnetorheological } \\
\text { fluid material } \\
\text { optimizations }\end{array}$ & Experiment & $\star \star \star \star$ & $\star \star$ & $\star \star \star$ & $\star \star$ & $\begin{array}{l}\text { Max braking } \\
\text { torque } 60 \mathrm{~N} \cdot \mathrm{m}\end{array}$ \\
\hline$[32]$ & $\begin{array}{c}\text { Natural } \\
\text { swing/lightw } \\
\text { eight }\end{array}$ & $\begin{array}{l}\text { Magnetorhe- } \\
\text { ological } \\
\text { damping }\end{array}$ & $\begin{array}{l}\text { (RSM) Mapping } \\
\text { Finite Element } \\
\text { Analysis (FEA) } \\
\text { amplitude response }\end{array}$ & Theory & $\star \star \star$ & $\star \star \star \star$ & $\star \star \star \star$ & $\star \star \star \star$ & $\begin{array}{l}71 \% \text { weight } \\
\text { reduction and } \\
\text { max damping } \\
\text { force } 698.55 \mathrm{~N}\end{array}$ \\
\hline$[33]$ & $\begin{array}{l}\text { High axial } \\
\text { thrust }\end{array}$ & $\begin{array}{l}\text { Motor stator } \\
\text { axial motion }\end{array}$ & $\begin{array}{l}\text { Spiralization of } \\
\text { motor rotor/stator }\end{array}$ & Experiment & $\star \star \star$ & $\star \star \star \star \star$ & $\star \star \star$ & $\star \star \star$ & $\begin{array}{l}\text { Rated thrust } \\
101 \mathrm{~N} \text { and max } \\
662 \mathrm{~N}\end{array}$ \\
\hline$[34,35]$ & $\begin{array}{l}\text { Active pow- } \\
\text { er/damping }\end{array}$ & $\begin{array}{c}\text { Hydraulic } \\
\text { energy storage } \\
\text { /release }\end{array}$ & $\begin{array}{l}\text { Rotary hydraulic } \\
\text { actuator }\end{array}$ & Theory & $\star \star \star$ & $\star \star \star$ & $\star \star$ & $\star \star \star$ & $\begin{array}{l}\text { Aerodynamic } \\
\text { damping and } \\
\text { max storage } \\
\text { stiffness } \\
4.15 \mathrm{MPa} \cdot \mathrm{cm}^{-3}\end{array}$ \\
\hline$[36]$ & $\begin{array}{c}\text { Energy } \\
\text { stor- } \\
\text { age/power } \\
\text { Generation }\end{array}$ & $\begin{array}{c}\text { Electrical } \\
\text { energy storage } \\
\text { /release } \\
\text { mechanism }\end{array}$ & $\begin{array}{c}\text { Generator/capacitor } \\
\text { energy } \\
\text { storage-release }\end{array}$ & Theory & $\star \star \star \star$ & $\star \star \star$ & $\star \star \star \star$ & $\star \star \star$ & $\begin{array}{c}\text { Knee joint } \\
\text { tracking error } \\
0.2^{\circ}\end{array}$ \\
\hline \multicolumn{10}{|c|}{ Elastic actuation } \\
\hline [29] & $\begin{array}{l}\text { Variable } \\
\text { knee stiff- } \\
\text { ness }\end{array}$ & $\begin{array}{l}\text { Series/parallel } \\
\text { elastic actua- } \\
\text { tor }\end{array}$ & $\begin{array}{l}\text { Level arm adjust- } \\
\text { ment }\end{array}$ & Prototype & $\star \star \star \star \star$ & $\star \star \star \star$ & $\star \star \star$ & $\star \star \star \star$ & $\begin{array}{c}\text { Torque in- } \\
\text { creased by } 20 \%\end{array}$ \\
\hline$[37]$ & $\begin{array}{l}\text { ago- } \\
\text { nist-antagoni } \\
\text { st actuation }\end{array}$ & $\begin{array}{l}\text { Dual series } \\
\text { elastic actua- } \\
\text { tors }\end{array}$ & Motor/screw/spring & Walking & $\star \star \star$ & $\star \star$ & $\star \star \star \star$ & $\star \star \star \star$ & $\begin{array}{c}\text { Metabolism } \\
\text { decreased by } \\
6.8 \%\end{array}$ \\
\hline$[38,39]$ & $\begin{array}{l}\text { Energy } \\
\text { storage via } \\
\text { clutch }\end{array}$ & $\begin{array}{l}\text { Clutchable } \\
\text { series elastic } \\
\text { actuator }\end{array}$ & Motor/clutch/spring & Walking & $\star \star \star \star$ & $\star \star$ & $\star \star \star \star$ & $\star \star \star \star$ & $\begin{array}{l}70 \% \text { reduction } \\
\text { in power con- } \\
\text { sumption }\end{array}$ \\
\hline$[40]$ & $\begin{array}{l}\text { Variable } \\
\text { stiffness } \\
\text { actuation } \\
\text { elasticity }\end{array}$ & $\begin{array}{c}\text { Dual variable } \\
\text { stiffness } \\
\text { actuators }\end{array}$ & $\begin{array}{l}\text { Motor/variable } \\
\text { stiffness spring }\end{array}$ & Walking & $\star \star \star$ & $\star \star$ & $\star \star$ & $\star \star$ & $\begin{array}{l}-1.25 \mathrm{~N} \cdot \mathrm{m} \cdot \mathrm{kg}^{-1} \\
\text { extensor torque }\end{array}$ \\
\hline$[41]$ & $\begin{array}{l}\text { Mus- } \\
\text { cle-based } \\
\text { actuation }\end{array}$ & $\begin{array}{l}\text { Inversed } \\
\text { series elastic } \\
\text { actuator }\end{array}$ & Motor/spring & Theory & $\star \star \star$ & $\star \star$ & $\star \star \star \star$ & $\star \star \star \star$ & $\begin{array}{c}71 \% \text { peak } \\
\text { power reduc- } \\
\text { tion in running }\end{array}$ \\
\hline$[42]$ & $\begin{array}{l}\text { Healthy knee } \\
\text { approximate } \\
\text { behavior/low } \\
\text { energy con- } \\
\text { sumption }\end{array}$ & $\begin{array}{l}\text { Semi-active } \\
\text { actua- } \\
\text { tors/tandem } \\
\text { elastic actua- } \\
\text { tors }\end{array}$ & $\begin{array}{l}\text { Motor-lockable parallel } \\
\text { spring-output }\end{array}$ & $\begin{array}{l}\text { Experi- } \\
\text { ment }\end{array}$ & $\star \star \star \star$ & $\star \star \star \star \star$ & $\star \star \star \star$ & $\star \star \star \star$ & $\begin{array}{l}2.7 \mathrm{~kg} \text { and } 65 \mathrm{~J} \\
\text { per step }\end{array}$ \\
\hline$[43,44]$ & $\begin{array}{l}\text { Variable } \\
\text { torsional } \\
\text { stiffness }\end{array}$ & $\begin{array}{l}\text { Cylindrical } \\
\text { elastic ele- } \\
\text { ment defor- } \\
\text { mation }\end{array}$ & $\begin{array}{l}\text { Motor/cylindrical } \\
\text { elastic element }\end{array}$ & $\begin{array}{l}\text { Experi- } \\
\text { ment }\end{array}$ & $\star \star \star \star$ & $\star \star \star$ & $\star \star$ & $\star \star \star \star$ & $\begin{array}{l}\text { Lower average } \\
\text { power con- } \\
\text { sumption }\end{array}$ \\
\hline$[45]$ & $\begin{array}{l}\text { Passive } \\
\text { elastic } \\
\text { energy } \\
\text { storage }\end{array}$ & $\begin{array}{l}\text { elastic actua- } \\
\text { tion }\end{array}$ & $\begin{array}{l}\text { Level arm adjust- } \\
\text { ment }\end{array}$ & Theory & $\star \star \star$ & $\star \star \star \star$ & $\star \star \star$ & $\star \star \star \star$ & $\begin{array}{l}3.4 \mathrm{~N} \cdot \mathrm{m} \cdot \mathrm{deg}^{-1}- \\
3.9 \mathrm{~N} \cdot \mathrm{m} \cdot \mathrm{deg}^{-1} \\
\mathrm{knee} \text { stiffness }\end{array}$ \\
\hline
\end{tabular}




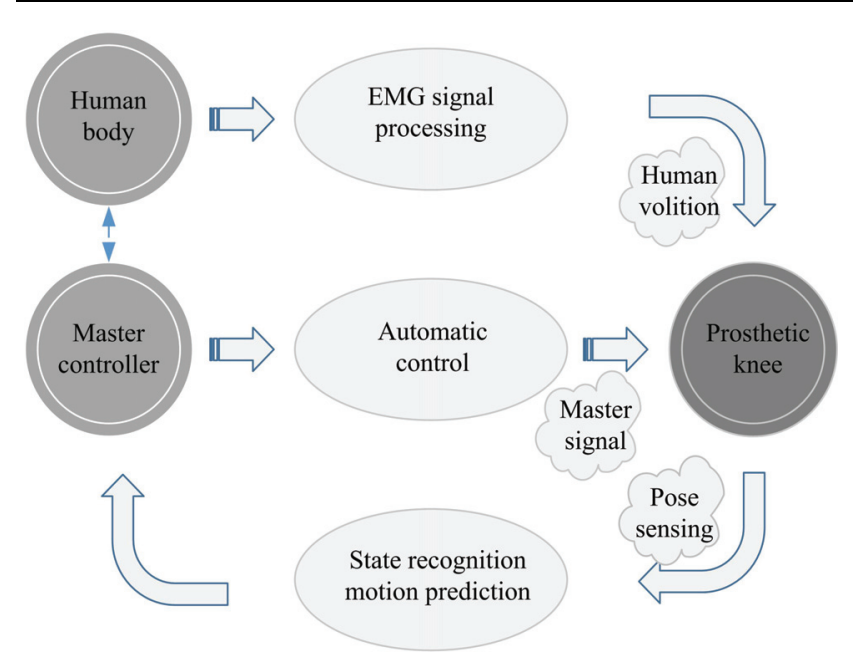

Fig. 5 Schematic diagram of the volitional-automatic fusion control.

motion intention of the amputee, thus achieving the volitional control of the robotic knee prosthesis ${ }^{[48-52]}$. The main flow of the sEMG-based prosthetic knee control is as follows: the sEMG signals of the lower limb are firstly collected by sensors and pre-processed by filtering, denoising, etc., and then pattern classification methods such as Quadratic Discriminant Analysis (QDA), and Linear Discriminant Analysis (LDA) are used to analyze the control intention of the amputee (buckling/flexion). Finally, the expected knee motion can be obtained by integrating the angular velocity calculated by the Principal Component Analysis (PCA).

\subsection{Mode identification and motion prediction}

The state recognition and the motion prediction can provide effective control and feedback parameters for the real-time control of the robotic knee prosthesis, thus enhancing the overall prosthetic control performance.

\subsubsection{Mode identification}

The mode identification of the robotic knee prosthesis includes the prosthetic knee state/phase identification and the state/phase switching/transition identification, among which the latter one still has many difficulties. Huang et al. proposed an sEMG-mechanical sensor fusion control of the robotic knee prosthesis ${ }^{[53]}$. Both the sEMG signal and mechanical signal are collected via the sEMG sensor and the inertial sensor installed on the residual limb. The Support Vector Machine (SVM) method is used to realize the continuous identification of the knee mode with the accuracy of $99 \%$ in the stance phase and $95 \%$ in the swing phase, which is more accurate than methods that use only the sEMG or mechanical sensors. Young et al. proposed a state mode identification method based on pattern training ${ }^{[54]}$. The authors used the Gaussian mixture model-based state classifier to realize the identification training, which includes the steady mode such as walking, stair ascent, etc., and mode switching such as from walking to stair ascent, from stair descent to walking, etc. The trained classifier can identify both the mode and mode switching with sufficient accuracy.

\subsubsection{Motion prediction}

The motion prediction can provide significant assistance for the automatic control of the prosthetic knee to improve the lower limb gait of the amputee. Kutilek et al. proposed a lower limb motion prediction method based on the Back-Propagation (BP) neural network and gait angle diagrams ${ }^{[5]}$. The knee-hip, knee-ankle, and hip-knee-ankle diagrams within one walking cycle are used to train the BP neural network, thereby enabling it to predict any movement of the lower extremities in walking cycles. Vallery et al. proposed a lower limb motion prediction method based on mapping ${ }^{[56]}$. Combined with residual motions of the amputees, pre-recorded lower limb motion data of healthy people under different motion states are statistically regressed to predict the movement of the lower limbs. Joshi et al. proposed a knee joint angle prediction method based on the contralateral knee joint angle and the trained adaptive fuzzy neural inference system ${ }^{[57]}$. The real-time input of the knee joint data in the contralateral side is used to infer the knee joint angle of the robotic knee prosthesis, thereby helping the amputee to realize the desired gait at different walking speeds. Moreover, Chen et al. proposed a method for recognizing knee joint torque based on surface EMG signals ${ }^{[58]}$. A knee joint torque calculation method based on the EMG model is established, where the Support Vector Machine (SVM) method is used to predict the knee joint torque. This method can successfully identify the required actuating torque for the knee joint and can provide theoretical support for the torque control of the robotic knee prosthesis. 


\subsection{Automatic control}

Lawson et al. proposed a prosthetic limb control method based on the Finite State Machine (FSM) ${ }^{[59]}$. Corresponding prosthetic joint actuating torque under different conditions is provided to enable the stair ascent/descent functions. The authors also realized the adaptive foot stabilization function via the same meth$\mathrm{od}^{[60]}$. To enhance the control effect of the FSM-based approaches, Liu et al. applied the Dempster Shafer theory-based state transition rule ${ }^{[61]}$ to improve the motion switching effect of the knee joint.

In addition to the FSM-based approaches, Xie et al. applied the neural network in the control of the robotic knee prosthesis to improve the walking gait of a four-bar mechanism robotic knee prosthesis actuated via the magnetorheological fluid damper ${ }^{[62]}$. Moreover, Ekkachai et al. also proposed a robotic knee prosthesis neural network predictive control method based on particle swarm optimization ${ }^{[63]}$. This method predicted the motion state of the robotic knee prosthesis in the first place. Then the damping compensation amount is provided in advance by the magnetorheological fluid damper prior to the active actuation, where the optimal voltage of the magnetorheological fluid damper is obtained by the particle swarm optimization to increase the gait performance.

Wen et al. also proposed a robotic knee prosthesis control method based on adaptive dynamic programming $^{[64]}$. Because the parameters of the robotic knee prosthesis controller in each state of the FSM are artificially given and lack versatility, the authors used adaptive dynamic programming to automatically tune the parameters in different working states, thus achieving the adaptive control of the prosthetic knee. In the meantime, Quintero proposed a prosthetic control method that unifies different periods of gait through virtual constraints driven by human-inspired phase variables $^{[65]}$. The controller is implemented for different walking speeds in the amputee biped walker model, and the feasibility of the control strategy is verified through experiments. What is more, Inoue et al. developed a control method to deal with changes in the gait parameters of the amputee ${ }^{[66]}$. The algorithm is evaluated using the level-ground gait database of healthy subjects. The results show that the precision and the recall of the proposed method are increased in both the stance phase and the swing phase of the level-ground walking.

\subsection{Summary of the control techniques of the robotic knee prosthesis}

The detailed summary of the control of the prosthetic knee joint is listed in Table 3. According to the simulation or experiment data in the introduced references, this section evaluated and compared the performance differences between mode identification, motion prediction, and automatic control. The evaluation includes four aspects: implementation (refers to the structure and algorithm of the control scheme), precision (refers to the accuracy of the identification, prediction or control of the algorithm), effectiveness (refers to the control effect of the control method on the prosthetic knee joint) and efficiency (refers to the stability and delay of control and other parameters that affect the control performance of the prosthetic knee joint). These four aspects of prosthetic knee joint control were scored respectively, and the performance was characterized as 1-5 five-point stars from low to high.

\section{Discussion}

\subsection{Development status of the robotic knee prosthesis}

In this section, the data in the references regarding the structure, actuation, and control of the prosthetic knee joint are quantitatively analyzed in depth. Because the structural parameters, actuation parameters, and control parameters of the prosthetic knee joint in each reference are not uniform, and the implementation schemes and effects of various prosthetic knee joints are also different, this paper adopted some typical comparative analysis method ${ }^{[67-69]}$ and evaluated the performance indices of the introduced structures, actuation, and control of the prosthetic knee joint.

\subsubsection{Structure}

According to the quantitative evaluation data of robotic knee structures in section $\mathbf{2}$, the structural performance indices of uniaxial, four-bar, and multi-axial prosthetic knee joints were drawn in Fig. 6.

It can be summarized from Fig. 6 that most robotic knee prostheses use mechanisms with fixed structural 
Sun et al.: Review of Recent Progress in Robotic Knee Prosthesis Related Techniques:

Table 3 Research summary and comparison in the control of the robotic knee prostheses

\begin{tabular}{|c|c|c|c|c|c|c|c|c|}
\hline Control & Refs. & Control features & Realization techniques & Implementation & Precision & Effectiveness & Efficiency & Control specifications \\
\hline \multirow{2}{*}{$\begin{array}{l}\text { Mode identi- } \\
\text { fication }\end{array}$} & {$[53]$} & $\begin{array}{l}\text { The fusion of surface } \\
\text { EMG and mechanical } \\
\text { sensors }\end{array}$ & $\begin{array}{l}\text { Pattern classifier (linear } \\
\text { discriminant analysis } \\
\text { method /support vector } \\
\text { machine, etc.) }\end{array}$ & $\star \star \star$ & $\star \star \star \star$ & $\star \star \star \star$ & $\star \star$ & $\begin{array}{l}\text { Recognition accuracy } \\
\text { of stance phase } 99 \% \text { / } \\
\text { swing phase } 95 \%\end{array}$ \\
\hline & {$[54]$} & $\begin{array}{l}\text { Pattern training-based } \\
\text { recognition }\end{array}$ & $\begin{array}{l}\text { Gaussian mixture mod- } \\
\text { el-based classifier }\end{array}$ & $\star \star \star \star$ & $\star \star \star \star \star ~$ & $\star \star \star \star \star$ & $\star \star \star \star$ & $\begin{array}{c}\text { Conversion accuracy } \\
93.9 \%\end{array}$ \\
\hline \multirow{3}{*}{$\begin{array}{l}\text { Motion pre- } \\
\text { diction }\end{array}$} & {$[55]$} & $\begin{array}{l}\text { The fusion of a } \\
\text { back-propagation } \\
\text { neural network and } \\
\text { joint angle diagram }\end{array}$ & $\begin{array}{l}\text { Neural network learning } \\
\text { of knee-hip, knee-knee, } \\
\text { and hip-knee-ankle }\end{array}$ & $\star \star \star \star \star ~$ & $\star \star \star \star$ & $\star \star \star \star$ & $\star \star \star$ & $\begin{array}{c}\text { Gait prediction accu- } \\
\text { racy } 80 \%\end{array}$ \\
\hline & {$[56]$} & Relational mapping & $\begin{array}{l}\text { Statistical regression of } \\
\text { pre-recorded residual } \\
\text { limb data }\end{array}$ & $\star \star \star \star$ & $\star \star \star \star$ & $\star \star \star \star$ & $\star \star \star$ & $\begin{array}{l}\text { Motion prediction } \\
\text { under different walking } \\
\text { speed }\end{array}$ \\
\hline & {$[57]$} & $\begin{array}{l}\text { Fusion of contralateral } \\
\text { knee angle and adaptive } \\
\text { fuzzy neural system }\end{array}$ & $\begin{array}{c}\text { Knee angle reasoning } \\
\text { based on trained adaptive } \\
\text { fuzzy neural inference } \\
\text { system }\end{array}$ & $\star \star \star$ & $\star \star \star$ & $\star \star \star$ & $\star \star \star$ & $\begin{array}{c}\text { Root mean square error } \\
\text { of angle prediction on } \\
3.4 \pm 1.4\end{array}$ \\
\hline \multirow{6}{*}{$\begin{array}{l}\text { Automatic } \\
\text { control }\end{array}$} & {$[59,60]$} & $\begin{array}{l}\text { Stair ascent } / \text { descent } \\
\text { based on finite state } \\
\text { machine }\end{array}$ & $\begin{array}{l}\text { Finite state ma- } \\
\text { chine-based stair as- } \\
\text { cent } / \text { descent motion } \\
\text { identification }\end{array}$ & $\star \star \star \star$ & $\star \star \star \star \star$ & $\star \star \star$ & $\star \star \star \star$ & $\begin{array}{l}\text { Free stair as- } \\
\text { cent/descent }\end{array}$ \\
\hline & {$[61]$} & $\begin{array}{l}\text { Dempster-Shafer state } \\
\text { transition rule-based } \\
\text { finite state machine }\end{array}$ & $\begin{array}{c}\text { Enhanced gait mode } \\
\text { transfer accuracy via } \mathrm{D}-\mathrm{S} \\
\text { theory }\end{array}$ & $\star \star \star \star$ & $\star \star \star \star \star$ & $\star \star \star$ & $\star \star \star \star$ & $\begin{array}{c}\text { Control error parameter } \\
\text { space less than } 1.5 \% \text { of } \\
\text { gait cycle }\end{array}$ \\
\hline & {$[63]$} & $\begin{array}{l}\text { Neural network predic- } \\
\text { tive control based on } \\
\text { particle swarm optimi- } \\
\text { zation }\end{array}$ & $\begin{array}{l}\text { Optimal magnetorheo- } \\
\text { logical fluid damper } \\
\text { compensation based on } \\
\text { neural network pros- } \\
\text { thetic motion prediction }\end{array}$ & $\star \star \star \star$ & 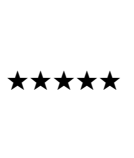 & $\star \star \star \star$ & $\star \star \star \star$ & $\begin{array}{l}\text { Enhanced walking gait } \\
\text { with less than } 1 \% \text { error }\end{array}$ \\
\hline & {$[64]$} & $\begin{array}{l}\text { Adaptive dynamic } \\
\text { programming }\end{array}$ & $\begin{array}{l}\text { Finite state machine } \\
\text { combined with adaptive } \\
\text { dynamic programming } \\
\text { (motion neural net- } \\
\text { work/evaluation neural } \\
\text { network) }\end{array}$ & $\star \star \star \star \star$ & $\star \star \star \star \star \star$ & $\star \star \star$ & $\star \star \star \star$ & $\begin{array}{l}87 \% \text { success rate in } \\
215 \text { gait cycles }\end{array}$ \\
\hline & {$[65]$} & $\begin{array}{l}\text { Virtual constraint } \\
\text { control }\end{array}$ & $\begin{array}{l}\text { Gait unification through } \\
\text { virtual constraints driven } \\
\text { by phase variables }\end{array}$ & $\star \star \star \star \star ~$ & $\star \star \star \star \star$ & $\star \star \star \star \star$ & $\star \star \star \star \star$ & $\begin{array}{l}\text { Shorten clinical ad- } \\
\text { justment time }\end{array}$ \\
\hline & {$[66]$} & $\begin{array}{l}\text { Control for changes of } \\
\text { femoral gait parameters }\end{array}$ & $\begin{array}{l}\text { Algorithms to accurately } \\
\text { identify and control } \\
\text { various gaits }\end{array}$ & $\star \star \star \star \star$ & $\star \star \star \star \star ~$ & $\star \star \star \star \star ~$ & $\star \star \star \star$ & $\begin{array}{c}\text { Stable level-ground } \\
\text { walking with } 99.5 \% \\
\text { accuracy }\end{array}$ \\
\hline
\end{tabular}

characteristics such as the single-axis mechanism or the four-bar mechanism, which only have one Degree of Freedom (DOF) and are less conducive to the realization of individual physiological characteristics. Additionally, some structures of current robotic knee prostheses may not fully simulate the knee joint, which might not bring in natural gait for above-knee amputees. However, by carefully analyzing and summarizing the robotic knee 


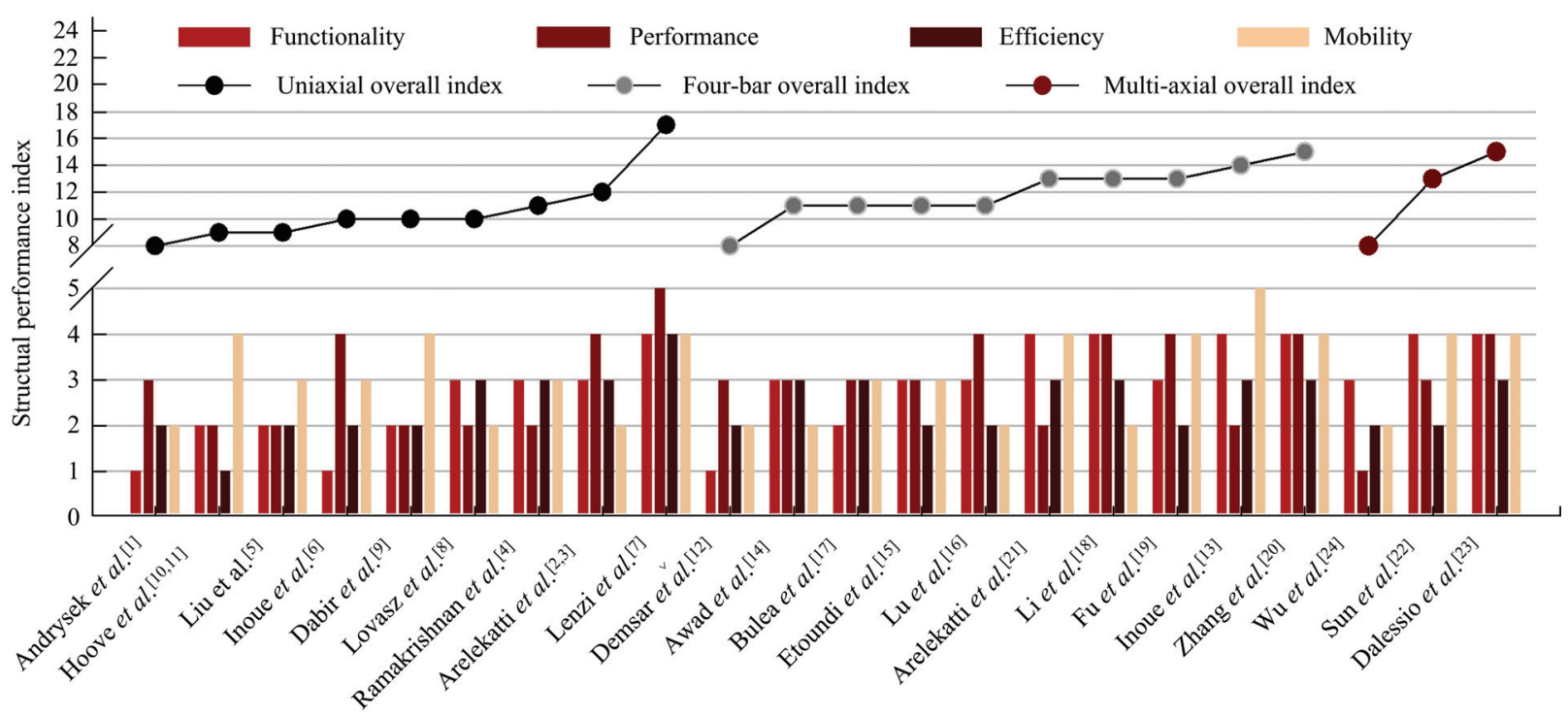

Fig. 6 Structural comparison of uniaxial, four-bar, and multi-axial robotic knee prostheses.

structures, it can be inferred from the development trend that the knee prosthesis has gradually become more bionic and lightweight with better mechanical performance. For example, the recent uniaxial robotic knee prosthesis developed by Lenzi et al. weighs only $1.7 \mathrm{~kg}$ (including battery), which is far more lightweight than the uniaxial ones proposed in previous years. Similarly, the four-bar knee proposed by Zhang et al. can absorb vibration during walking via dampers, demonstrating better mechanical performance than convention rigid four-bar knees. In addition, the multi-axial robotic knee prosthesis designed by Sun et al. can also provide subjects with adjustable bionic performance, which outperforms previous four-bar robotic knee prostheses with fixed bionic features. Purposeful structural designs are beneficial to the miniaturization of the actuation and control system, making the robotic knee prosthesis more adapted to the gait diversification and the multi-modality of human lower limb movement characteristics (such as running, stair ascent/descent, jumping, etc.).

\subsubsection{Actuation}

According to the quantitative evaluation data of robotic knee actuation techniques in section $\mathbf{3}$, the actuating performance indices of the rigid actuation and elastic actuation are plotted in Fig. 7.

As discussed in section $\mathbf{3}$, the purely passive robotic knee prosthesis may not achieve the active swing nec- essary for a natural walking gait. Some of the semi-active and fully active knee prostheses are short of shock absorption and knee energy reuse functions. However, after summarizing current actuation techniques via Fig. 7, it can be found that the elastic actuation or hybrid elastic actuation is theoretically more energy-saving and can enable the robotic knee prosthesis with more stable and smooth movement.

Yet, this emerging actuation technique has not been commercially applied. At present, the energy-saving effect introduced by the elastic actuation may not compensate for the increase in power consumption caused by the additional weight of the elastic actuation component. What is more, the trade-off between the device price and performance might also slow down its commercial applications. From the viewpoint of the authors, the goal of weight reduction should be taken seriously for its practical and commercial application in the design of elastic actuators. Some lightweight elastic actuation approaches such as the dielectric elastomer, the magnetorheological fluid, the electrorheological fluid, the pneumatic actuation, etc., might bring desired performance while the weight of the actuator may be significantly reduced.

\subsubsection{Control}

According to the quantitative evaluation data of robotic knee control techniques in section $\mathbf{4}$, the control performance indices of pattern recognition, motion 


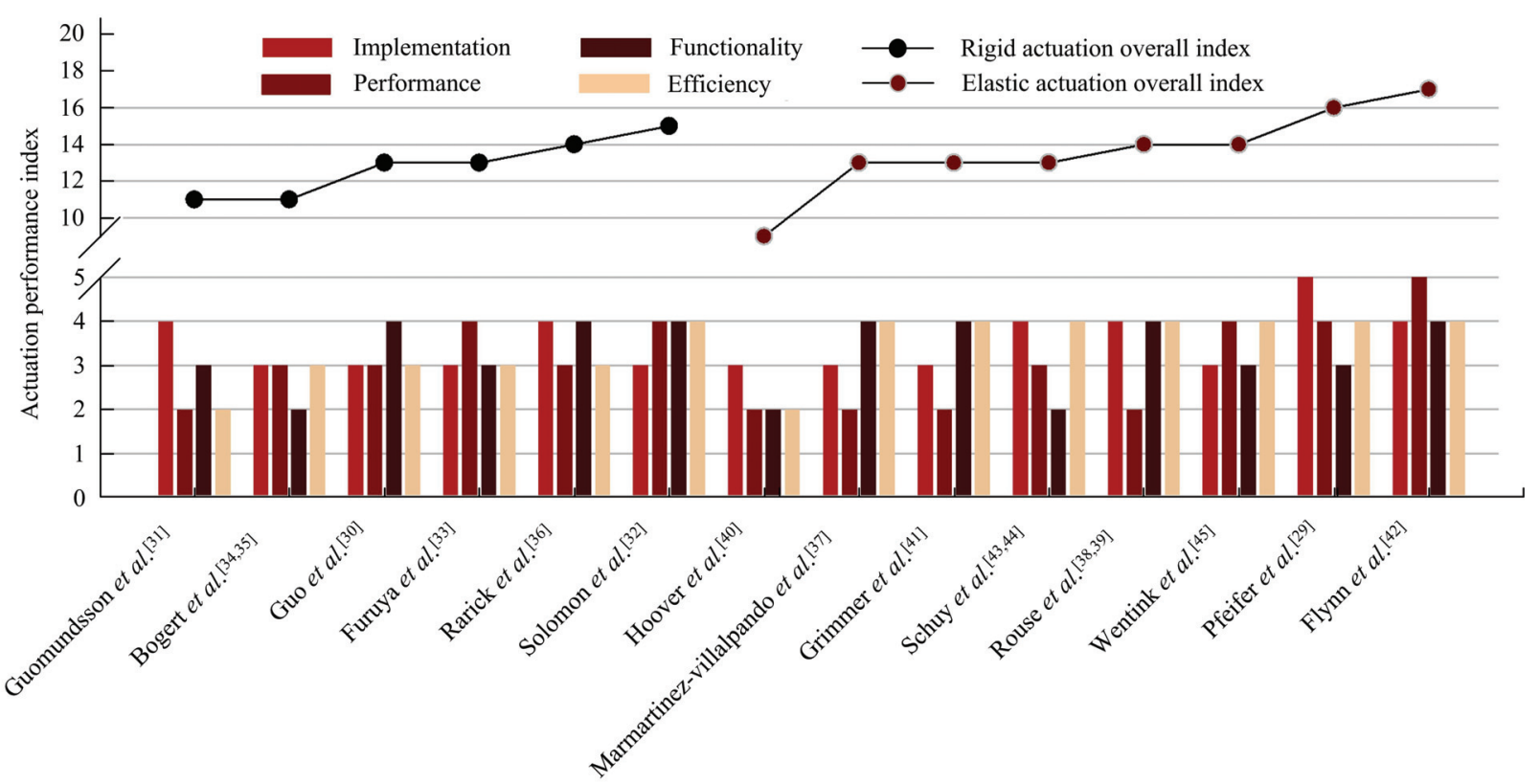

Fig. 7 Comparison between rigid and elastic actuation techniques of robotic knee prostheses.

prediction, and automatic control are plotted and in Fig. 8.

The purpose of the prosthetic knee control is to realize expected gait movements for the amputee. As the low-level control of the robotic knee prosthesis belongs to the complex nonlinear human-machine interaction, the realization of precise lower limb motion tracking and control still needs improvement in algorithms and hardware. In addition, the transition identification between each locomotion mode still hindered the improvement of gait detection accuracy. However, it can be found from Fig. 8 that the recent automatic control methods based on artificial intelligence (such as machine learning, reinforcement learning, etc.) have gradually shown better control effects. For example, the algorithms proposed by Inoue et al. show a stable level-ground walking with $99.5 \%$ accuracy, which means a walking control error will only occur after more than two hundred steps. Certainly, to further enhance the control performance of the robotic knee prosthesis, it is a better (maybe not optimal) approach to collect as many signals as possible (any volitional signals and gait signals) as long as the algorithm complexity is within the limit of the hardware computing power.

\subsection{New explorations in robotic knee prostheses}

By analyzing the researches in the aspect of struc- tures, actuation, and co050trols, it is summarized that the bionic functionality, energy efficiency, and natural gait are three areas that could be focused on to realize performance enhancement for the robotic knee prosthesis. As a consideration of these three areas, the following feasible research discussions are listed.

\subsubsection{Customized lightweight bionic knee joint structure}

From the very beginning of the research of the passive/semi-active robotic knee prosthesis, the relative rotation/sliding bionic motion characteristics between the human thigh and shank have become the research focus, where the fundamental four-bar robotic knee prosthesis and subsequent five-bar, six-bar ones that could simulate this knee motion characteristics effectively improved the joint stability and walking gait performance. With the development of modern micro-electromechanical technology, the active robotic knee prosthesis has become a new high ground for prosthetic research due to its better human-like actuating characteristics.

However, there are still some structural issues that need to be solved.

(1) Space and weight requirements for high-efficiency actuating devices significantly reduce the bionic design space of the knee mechanism itself. 


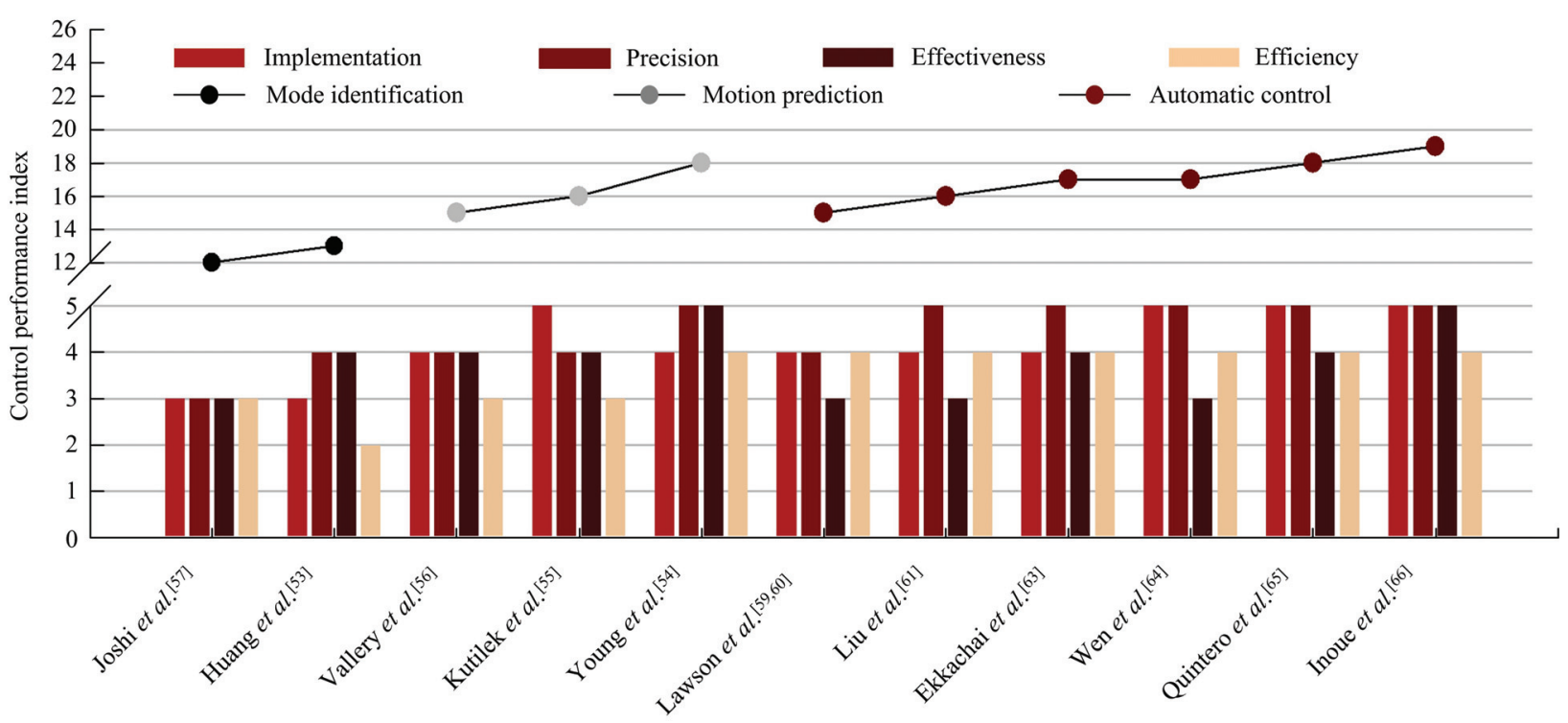

Fig. 8 Comparison between mode identification, motion prediction, and automatic control of robotic knee prostheses.

(2) The bulky multi-bar mechanism may also not be conducive to the lightweight requirements of the active robotic knee prosthesis.

Designers have to make a trade-off between bionic and lightweight: "active lightweight" or "active bionic"? The actual conflict between them is that the bionic multi-axis knee prosthesis cannot meet the lightweight requirements of the actively actuated knee prosthesis. For some researchers, the lightweight and battery-life benefits of abandoning the bionic multi-bar mechanism are more significant than the invisible bionic performance. Therefore, to realize the fusion and coexistence of active actuation and bionic structure, the following possible research directions could be considered to realize customized lightweight bionic knee joint for unilateral and bilateral above-knee amputees.

(1) Explore some quasi-uniaxial lightweight bionic joint configurations such as non-circular gears, compliant joints, etc.

(2) Design a set of configuration adjustment mechanisms suitable for different patients.

\subsubsection{Highly efficient compact bionic actuation}

The human knee joint can achieve diversified and complex movements due to its extremely high-power density and efficient energy recovery mechanism. In daily life, the human body has unpredictable behavior and will switch randomly in real-time among the movement modes of slow/normal/fast walking, slope, stairs, standing up, and sitting down, where the power of the knee joint will alternately switch between positive and negative power states. When the knee joint is in a negative power state, it will release mechanical energy to the outside instead of applying actuating energy to it. This phenomenon will bring the following challenges to the actuator of the robotic knee prosthesis.

(1) The negative power state of the knee joint is highly related to the motion state of the subject and has the characteristics of high frequency, short period, and high power.

(2) If the negative power of the knee joint is not handled well, the energy consumption of the actuator will increase sharply due to braking.

In the human body, the mechanical energy released by the negative work of the knee joint will be transmitted to the hip and ankle joints via the gastrocnemius, semitendinosus, and rectus femoris muscles, so as to achieve energy absorption/reuse and reduce the actual consumption of human metabolism. Therefore, to achieve the efficient and active actuation of the robotic knee prosthesis, the following possible research directions could be considered to reduce the hardware requirements for the peak power and torque of the joint actuator during active actuation. 
(1) Reduce the weight of the joint and increase the power density of the joint actuator, including applying lightweight materials and topology optimization to reduce weight, installing high power density motors and efficient transmission devices, and using a power supply system with higher power density.

(2) Explore the power characteristics of the knee joint in multi-mode motion from the perspective of energy recovery by storing/buffering energy fluctuations based on physical hardware such as elastic elements or power generation systems as well as necessary software algorithms.

\subsubsection{Personalized daily multi-mode gait adaptation}

Nowadays, although the gait recognition algorithm can realize high accuracy gait recognition in typical walking scenes (including level-ground, ramp, stairs), for large movements such as running and jumping in daily life, gait recognition is still challenging. In addition, different patients have different characteristics of gait signal mutations, which reduces the processing ability of one single gait model. Therefore, the following gait issues still need to be solved:

(1) individual gait data differences between various amputees and time distortion fluctuations caused by the difference in walking speed;

(2) the transition problem between gaits has always been a difficult point for current gait recognition and prediction algorithms.

What is more, the demand for hardware sensors in gait recognition may bring a difficulty to accuracy improvement:

(1) it is difficult to ensure the orientation of the sensor in practical applications as large movements will cause the sensor to lose;

(2) there will be a time difference between input and output due to the calculation time of gait recognition.

Because the accelerometer is sensitive to the direction, the uncertainty of the sensor orientation will lead to confusion in the collected data. Furthermore, an excessive delay will lead to poor user experience and reduce user comfort, which will even cause gait disturbances. Moreover, differences in patient wear, including clothing outside the skin, shoes, and weight-bearing conditions, will also cause negative disturbances and affect the sensor data accuracy. Therefore, the research of daily adaptive multi-mode gait still needs to explore algorithms with higher generalization capabilities as well as high precision sensing. The following possible research direction could be considered:

(1) the deep learning-based approaches gradually show their advantages in big data processing with high generalization.

(2) exploring new non-contact sensing technologies might be a new approach to improve the adaptive ability of gait recognition.

\section{Conclusion}

The robotic knee prosthesis is a key apparatus for the rehabilitation of patients with above-knee amputations, the research theories and methods of which are the frontier embodiment of mechatronics and human-computer interaction technologies. This paper made an in-depth investigation on the development of robotic knee prostheses in the past ten years and categorized them based on their functionality and mutual relationships. Detailed qualitative and quantitative analysis of its structural design, actuation, and control strategies are presented. In addition, challenges and innovations in the development of robotic knee prostheses are also expanded. The structure of the robotic knee prosthesis is gradually becoming more bionic and lighter with better mechanical performance. The elastic actuation and elastic hybrid actuation are showing better energy-saving effect, and bionic actuation features. Control methods based on artificial intelligence are gradually improving the daily use of robotic knee prostheses. The knee prosthesis-related techniques are essentially a concrete instance of mechatronic wearable devices, which require more breakthroughs and innovations in basic mechanical engineering, material technology, automatic control, and computer science. However, as the authors' prospect, the robotic knee prosthesis will gradually become more bionic, intelligent, and energy-efficient to help amputation patients to achieve their physical and psychological returns.

\section{Acknowledgment}

This work was supported by the National Natural Science Foundation of China (Grant Nos. 62003060, 
51975070 and 62033001), and the National Key Research and Development Program of China under Grant 2020YFB1313000.

Open Access This article is licensed under a Creative Commons Attribution 4.0 International License, which permits use, sharing, adaptation, distribution and reproduction in any medium or format, as long as you give appropriate credit to the original author(s) and the source, provide a link to the Creative Commons licence, and indicate if changes were made.

The images or other third party material in this article are included in the article's Creative Commons licence, unless indicated otherwise in a credit line to the material. If material is not included in the article's Creative Commons licence and your intended use is not permitted by statutory regulation or exceeds the permitted use, you will need to obtain permission directly from the copyright holder.

To view a copy of this licence, visit http://creativecommons.org/licenses/by/4.0/.

\section{References}

[1] Andrysek J, Klejman S, Torres-Moreno R, Heim W, Steinnagel B, Glasford S. Mobility function of a prosthetic knee joint with an automatic stance phase lock. Prosthetics and Orthotics International, 2011, 35, 163-170.

[2] Arelekatti V M, Winter A G. Design of a fully passive prosthetic knee mechanism for transfemoral amputees in India. IEEE International Conference on Rehabilitation Robotics (ICORR), Singapore, 2015, 350-356.

[3] Arelekatti V M, Winter A G. Design of mechanism and preliminary field validation of low-cost, passive prosthetic knee for users with transfemoral amputation in India. Proceeding of the ASME International Design Engineering Technical Conferences and Computers and Information in Engineering Conference, Boston, USA, 2015.

[4] Ramakrishinan T. Asymmetric Unilateral Transfemoral Prosthetic Simulator. Department of Mechanical Engineering, Master's thesis, University of South Florida, Florida, USA, 2014.

[5] Liu M, Datseris P, Huang H H. A prototype for smart prosthetic legs-analysis and mechanical design. Advanced Materials Research, 2012, 403-408, 1999-2006.

[6] Kou I, Takahiro W, Ryuchi H. Novel knee joint mechanism of transfemoral prosthesis for stair ascent. IEEE 13th International Conference on Rehabilitation Robotics (ICORR),

\section{Seattle, USA, 2013, 7, 24-26}

[7] Lenzi T, Cempini M, Hargrove L, Kuiken T. Design, development, and testing of a lightweight hybrid robotic knee prosthesis. The International Journal of Robotics Research, 2018, 37, 953-976.

[8] Lovasz E C, Ciupe V, Modler K H, Gruescu C M, Hanke U, Maniu I, Margineanu D. Experimental design and control approach of an active knee prosthesis with geared linkage. New Advances in Mechanisms, Transmissions and Applications Springer Netherlands, 2014, 17, 149-156..

[9] Yaghoub D, Siamak N, Mohammad R E, Saeed Z, David M. A powered prosthetic knee joint inspired from musculoskeletal system. Biocybernetics and Biomedical Engineering, 2013, 33, 118-124.

[10] Hoover C D, Fite K B. Development of a powered-knee transfemoral prosthesis prototype. Proceedings of the ASME 2011 Summer Bioengineering Conference, Pennsylvania, USA, 2011, 531-532.

[11] Hoover C D, Fulk G D, Fite K B. Stair ascent with a powered transfemoral prosthesis under direct myoelectric control. IEEE/ASME Transactions on Mechatronics, 2013, 18, 1191-1200.

[12] Demsar I, Supej M, Vidrih Z, Duhovnik J. Development of prosthetic knee for alpine skiing. Journal of Mechanical Engineering, 2011, 57, 768-777.

[13] Inoue K, Tanaka T, Wada T, Tachiwana S. Development of a passive knee mechanism that realizes level walk and stair ascent functions for transfemoral prosthesis. 6th IEEE International Conference on Biomedical Robotics and Biomechatronics, Singapore, 2016, 522-527.

[14] Awad M, Tee K S, Dehghani A. Analysis and performance of a semi-active prosthetic knee. Proceedings of the International Conference on Mechanical Engineering and Mechatronics, Ottawa, Canada, 2012, 213.

[15] Etoundi A C, Lock R J, Vaidyanathan R, Burgess S C. A bio-inspired condylar knee joint for knee prosthetics. International Journal of Design \& Nature and Ecodynamics, 2013, 8, 213-225.

[16] Lu J A, Chen Y H. Topology optimisation and customisation of a prosthetic knee joint design. International Journal of Computer Integrated Manufacturing, 2013, 26, 968-976.

[17] Bulea T C, Kobetic R, To C S, Audu M L, Schnellenberger J $\mathrm{R}$, Triolo R J. A variable impedance knee mechanism for controlled stance flexion during pathological gait. IEEE/ASME Transactions on Mechatronics, 2012, 17, 822-832.

[18] Li F, Zhang F M, Ding R X, Xie H L. Mechanism design and 
shock-absorbing performance analysis of prosthesis knee joint with meniscus. Machinery Design \& Manufacture, 2016, 1, 161-164.

[19] Fu H Q, Zhang X F, Wang X T, Yang R, Li J, Wang L, Zhang N, Li G, Liu T, Fan B F, Inoue Y. A novel prosthetic knee joint with a parallel spring and damping mechanism. International Journal of Advanced Robotic Systems, 2016, 13, 1-9.

[20] Zhang X F, Fu H Q, Wang X T, Li G, Yang R, Liu Y. Design of a novel bionic prosthetic knee joint. Assembly Automation, 2016, 36, 398-404.

[21] Arelekatti V N M, Winter V A G. Design and preliminary field validation of a fully passive prosthetic knee mechanism for users with transfemoral amputation in India. Journal of Mechanisms and Robotics, 2018, 10, 031007.

[22] Sun Y X, Ge W J, Zheng J, Dong D B. Design and evaluation of a prosthetic knee joint using the geared five-bar mechanism. IEEE Transactions on Neural Systems and Rehabilitation Engineering, 2015, 23, 1031-1038.

[23] Alessio J, Russell K, Lee W T, Sodhi R S. On the application of rrss motion generation and rrss axode generation for the design of a concept prosthetic knee. Mechanics Based Design of Structures and Machines, 2017, 45, 406-414.

[24] Wu B, Chen Z B, Cheng M. Design and simulation of a new prosthetic knee joint. Machinery Design \& Manufacture, 2015, 06, 5-8.

[25] Wu X Y, Zhai S J, Hao Q. Analysis and simulation of prosthetic knee joint four bar mechanism. Journal of Machine Design, 2011, 09, 42-45.

[26] Zhang L J, Lu W T, Cao X M. Structural optimal design of four-bar bionic knee joint. Machine Tool \& Hydraulics, 2015, 09, 67-70.

[27] Ghaemi N, Zohoor H, Ghaemi H. Dynamic performance of different knee mechanisms with compliant joints. Scientia Iranica, 2016, 23, 1055-1063.

[28] Pfeifer S, Riener R, Vallery H. An actuated transfemoral prosthesis with optimized polycentric knee joint. 4th IEEE RAS \& EMBS International Conference on Biomedical Robotics and Biomechatronics, 2012, 1807-1812.

[29] Pfeifer S, Pagel A, Riener R, Vallery H. Actuator with angle-dependent elasticity for biomimetic transfemoral prostheses. IEEE/ASME Transactions on Mechatronics, 2015, 20, 1384-1394.

[30] Guo H T, Liao W H. A novel multifunctional rotary actuator with magnetorheological fluid. Smart Materials and Structures, 2012, 21, 65012-65020.

[31] Guomundsson K H. Design of a Magnetorheological Fluid for an MR Prosthetic Knee Actuator with an Optimal Geometry, PhD thesis, University of Iceland, Iceland, 2011.

[32] Solomon S, Sujatha C, Sujatha S. Optimal design of an MR damper valve for prosthetic knee application. Journal of Mechanical Science and Technology, 2018, 32, 2959-2965.

[33] Furuya Y, Mikami T, Suzuki T, Fujimoto Y. On an active prosthetic knee joint driven by a high thrust force helical motor. 39th Annual Conference of the IEEE Industrial Electronics Society, 2013, 5894-5899.

[34] Bogert A J V D, Samorezov S, Davis B L, Smith W A. Modeling and optimal control of an energy-storing prosthetic knee. Journal of Biomechanical Engineering, 2012, 134, 051007.

[35] Wilmot T, Thomas G, Montavon B, Rarick R, Van dBAJ, Szatmary S, Simon D J, Smith W, Samorezov S. Biogeography-based optimization for hydraulic prosthetic knee control. Medical Cyber-Physical Systems Workshop, Philadelphia, Pennsylvania, 2013, 18-25.

[36] Rarick R, Richter H, Bogert A V D, Dan S, Warner H, Barto T. Optimal design of a transfemoral prosthesis with energy storage and regeneration. American Control Conference IEEE, 2014, 4108-4113.

[37] Martinez-Villalpando E C, Mooney L, Elliott G, Herr H. Antagonistic active knee prosthesis a metabolic cost of walking comparison with a variable-damping prosthetic knee. Annual International Conference of the IEEE Engineering in Medicine and Biology Society, 2011, 8519-8522.

[38] Rouse E J, Mooney L M, Herr H. Clutchable series-elastic actuator: Implications for prosthetic knee design. The International Journal of Robotics Research, 2014, 33, 1611-1625.

[39] Rouse E J, Mooney L M, Martinez-Villalpando E C, Herr H. Clutchable series-elastic actuator: Design of a robotic knee prosthesis for minimum energy consumption. 13th International Conference on Rehabilitation Robotics, Seattle, USA, 2013, 1-6.

[40] Hoover C D, Fite K B. A configuration dependent muscle model for the myoelectric control of a transfemoral prosthesis. IEEE International Conference on Rehabilitation Robotics, Zurich, Switzerland, 2011, 1-6.

[41] Grimmer M, Seyfarth A. Stiffness adjustment of a series elastic actuator in a knee prosthesis for walking and running: The trade-off between energy and peak power optimization. IEEE/RSJ International Conference on Intelligent Robots and Systems, 2011, 1811-1816.

[42] Geeroms J, Flynn L, Jimenez-Fabian R, Vanderborght B, Lefeber D. Design and energetic evaluation of a prosthetic 
knee joint actuator with a lockable parallel spring. Bioinspiration \& Biomimetics, 2017, 12, 026002.

[43] Schuy J, Beckerle P, Wojtusch J, Rinderknecht S, Stryk O. Conception and evaluation of a novel variable torsion stiffness for biomechanical applications. 4th IEEE RAS \& EMBS International Conference on Biomedical Robotics and Biomechatronics (BioRob), 2012, 713-718.

[44] Beckkerle P. Human-Machine-Centered Design and Actuation of Lower Limb Prosthetic Systems. Darmstadt University of Technology, Hessen, Germany, 2014.

[45] Wentink E C, Koopman H, Stramigioli S, Rstramigioli J S, Veltink P H. Variable stiffness actuated prosthetic knee to restore knee buckling during stance: A modeling study. Medical engineering \& physics, 2013, 35, 838-845.

[46] Ma Y L, Xu W L, Meng M, Luo Z Z, Yang J Q. Adaptive control for intelligent lower limb prosthesis based on neural network. Journal of Zhejiang University (Engineering Science), 2010, 44, 1373-1376. (in Chinese)

[47] Ma Y L, Luo Z Z, Meng M, She Q S. Adaptive control for intelligent lower-limb prosthesis based on LVQ neural network. 7th National Symposium on Rehabilitation Medicine Engineering and Rehabilitation Engineering, 2010, 61-66.

[48] Ha K H, Varol H A, Goldfarb M. Volitional control of a prosthetic knee sing surface electromyography. IEEE Transactions on Biomedical Engineering, 2011, 58, 144-151.

[49] Hargrove L J, Simon A M, Lipschutz R D,Finucane S B, Kuiken T A. Real-time myoelectric control of knee and ankle motions for transfemoral amputees. Jama the Journal of the American Medical Association, 305, 15, 1542-1544.

[50] Hargrove L, Simon A M, Finucane S B, Lipschutz R D. Myoelectric control of a powered transfemoral prosthesis during non-weight-bearing activities. Proceedings of the MyoElectric Controls/Powered Prosthetics Symposium Fredericton, New Brunswick, Canada, 2011.

[51] Hargrove L J, Simon A M, Lipschutz R, Finucane S B, Kuilen T A. Non-weight-bearing neural control of a powered transfemoral prosthesis. Journal of Neuroengineering and Rehabilitation, 2013, 10, 62-62.

[52] Dawley J A, Fite K B, Fulk G D. EMG control of a bionic knee prosthesis: Exploiting muscle co-contractions for improved locomotor function. IEEE 13th International Conference on Rehabilitation Robotics (ICORR), Seattle, USA, 2013, 1-6.

[53] Huang H, Zhang F, Hargrove L J, Dou Z, Rogers D R, Englehart K B. Continuous locomotion-mode identification for prosthetic legs based on neuromuscular-mechanical fu- sion. IEEE Transactions on Biomedical Engineering, 2011, 58, 2867-2875.

[54] Young A J, Simon A M, Hargrove L J. A training method for locomotion mode prediction using powered lower limb prostheses. IEEE Transactions on Neural Systems and Rehabilitation Engineering, 2014, 22, 671-677.

[55] Kutilek P, Farkasova B. Prediction of lower extremities' movement by angle-angle diagrams and neural networks. Acta of Bioengineering and Biomechanics, 2011, 13, 57-65.

[56] Vallery H, Burgkart R, Hartmann C, Mitternacht J, Riener R, Buss M. Complementary limb motion estimation for the control of active knee prostheses. Biomedizinische Technik/Biomedical Engineering, 2011, 56, 45-51.

[57] Joshi D, Mishra A, Anand S. ANFIS based knee angle prediction: An approach to design speed adaptive contra lateral controlled AK prosthesis. Applied Soft Computing, 2011, 11, 4757-4765.

[58] Chen L L, Yang P, Geng Y L, Liu Z J. Torque recognition of knee joint based on electromyography. Journal of Central South University: Science and Technology, 2013, 44(SUPPL.2), 117-121. (in Chinese)

[59] Lawson B E, Varol H A, Huff A, Erdemir E, Goldfarb M. Control of stair ascent and descent with a powered transfemoral prosthesis. IEEE Transactions on Neural Systems and Rehabilitation Engineering, 2013, 21, 466-473.

[60] Lawson B E, Varol H A, Goldfarb M. Standing stability enhancement with an intelligent powered transfemoral prosthesis. IEEE Transactions on Biomedical Engineering, 2011, 58, 2617-2624.

[61] Liu M, Zhang F, Datseris P, Huang H. Improving finite state impedance control of active-transfemoral prosthesis using dempster-shafer based state transition rules. Journal of Intelligent \& Robotic Systems, 2014, 76, 461-474.

[62] Xie H L, Liu Z B, Yang J Y, Sheng Z Q, Xu Z W. Modelling of magnetorheological damper for intelligent bionic leg and simulation of knee joint movement control. International Journal of Simulation Modelling (IJSIMM), 2016, 15, 144-156.

[63] Ekkachai K, Nilkhamhang I. Swing phase control of semi-active prosthetic knee using neural network predictive control with particle swarm optimization. IEEE Transactions on Neural Systems \& Rehabilitation Engineering, 2016, 24, 1169-1178.

[64] Wen Y, Si J, Gao X, Huang S, Huang H. A new powered lower limb prosthesis control framework based on adaptive dynamic programming. IEEE Transactions on Neural Networks \& Learning Systems, 2017, 28, 2215-2220. 
[65] Quintero D. Virtual Constraint Control of Powered Prosthetic Pegs: Unifying the Gait Cycle, $\mathrm{PhD}$ thesis, University of Texas at Dallas, Richardson City, USA, 2018.

[66] Inoue K, Fukuda T, Wada T. A control method for transfemoral prosthetic knees based on thigh angular motion. 41 st Annual International Conference of the IEEE Engineering in Medicine and Biology Society (EMBC), Berlin, Germany, 2019, 6644-6647.

[67] Soriano J F, Rodríguez J E, Valencia L A. Performance comparison and design of an optimal polycentric knee mechanism. Journal of the Brazilian Society of Mechanical Sciences and Engineering, 2020, 42, 221.

[68] Han D L, Zhang R, Zhang H, Hu Z Y, Li J Q. Mechanical performances of typical robot feet intruding into sands. Energies, 2020, 13, 1867.

[69] Carbone G, Rossi C, Savino S. Performance comparison between FEDERICA hand and LARM hand. International Journal of Advanced Robotic Systems, 2015, 12, 90. 